\title{
ULWA VERB CLASS MORPHOLOGY ${ }^{1}$
}

\author{
ANDREW KoOnTZ-GARbOdEN
}

UNIVERSITY OF MANCHESTER

This paper provides a detailed description and analysis of Ulwa (Misumalpan; Nicaragua) verb class morphology. Taking as a point of departure the previous literature on the topic (Hale and Salamanca 2002, Hale and Keyser 2002, and Juarros 2003), I show that the facts are more complicated than has been appreciated, and that previous theoretical claims based on facts from the language are not justified. The verb class markers - $t a-$ and $-p a-$, I argue, are verbalizers of precategorial roots, while - $d a$ - and - $w a$ - are shown to serve, among other functions, as anticausativizers. The contrast in the two broad classes of verb class marker is shown to have significant consequences for the lexical semantics, syntax, and morphology of verbs in the language, leading to an understanding of a range of previously poorly understood and undocumented facts of the language.

[KEYwORDS: Ulwa, Misumalpan, argument structure, verb semantics, verb morphology]

1. Introduction. Ulwa is an endangered Misumalpan language whose system of verb class morphology has played something of a prominent role in recent years in the development of theories of argument structure (Hale and Salamanca 2002, Hale and Keyser 2002, and Juarros 2003). ${ }^{2}$ As has

${ }^{1}$ I gratefully acknowledge the collaboration of the Ulwa Yulka Tunak Muihka Balna (UYUTMUBAL), Karawala, RAAS, Nicaragua, and the community of Karawala for welcoming me into their community and sharing their language and culture with me. The work reported here would not have been possible without the help, in particular, of Francisco Santiago, Alberto Santiago, Abanel Lacayo, Lorinda Martínez, Clementina Simon, and Kandler Santiago. I am also indebted to Tom Green, Nubia Ordóñez, Melissa Koontz-Garboden, Guillermo Mclean, Melvin James Olegario, Elena Benedicto, and IPILC-URACCAN in numerous ways for facilitating my work with the Ulwa Language Project. For comments on versions of this manuscript (at various stages), I owe thanks to Beth Levin, Paul Kiparsky, Peter Sells, Eva Schultze-Berndt, Judith Tonhauser, John Beavers, Elena Benedicto, and especially IJAL's anonymous associate editor and two anonymous referees. Financial support for the research reported here was provided in part by a Fulbright-Hays Dissertation Research Abroad Fellowship, Graduate Research Funds from the Department of Linguistics at Stanford University, and a Stanford University Graduate Research Abroad grant.

${ }^{2}$ The orthography used in the Ulwa examples is that adopted by the Ulwa Language Project, itself an adaptation of the Miskitu orthography devised by Moravian missionaries (Green 1999:33). The orthographic conventions are mostly straightforward and are discussed by Green (1999:33ff.). The less self-explanatory conventions are: $(a)$ use of the circumflex above a vowel for contrastively long vowels; $(b) n g$ is used for the velar nasal; $(c) h$ following any of the sonorants $l, r, n, n g, m$ indicates that the sonorant is voiceless.

Glossing conventions throughout the paper are as follows: ADJ the morpheme appearing on Ulwa words naming property concept states (Koontz-Garboden and Francez 2009); AUX

[IJAL, vol. 75, no. 4, October 2009, pp. 453-512]

(c) 2009 by The University of Chicago. All rights reserved.

0020-7071/2009/7504-0001\$10.00 
been observed in this work, Ulwa verbs in the general cases are divided into four major morphological classes according to the verb class marker that appears after the verbal root: $-d a-,-p a-,-w a-$, and $-t a-.{ }^{3}$ Verbs in each of these classes are illustrated in (1).

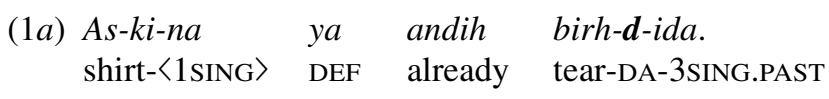

'My shirt has already torn'. (notes, 985)

(1b) Il-w-ing

ascend-WA-1SING.PRFCT

kau atak ya

bah-w-ida.

break-WA-3SING.PAST

'When I climbed up the stairway, it broke'. (dict)

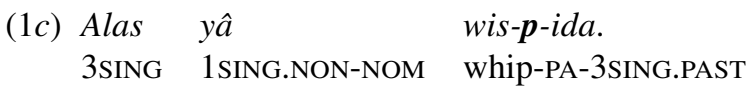

'S/he whipped me'. (dict)

(1d) Kuh-ki ya kum-da-sa bahangh pûh-t-uting.

fire-1SING DEF burn-DA-NEG because blow-TA-1SING.FUT

'Since my fire is not burning, I'm going to blow on it'. (dict)

The allure of the Ulwa verb class morphology in the theoretical literature on argument structure has been its implications for the system of transitivity alternations in the language. As discussed by Hale and Salamanca (2002), verb roots in Ulwa often participate in the causative/inchoative alternation; for example, they have an inchoative variant in the $-d a / w a$ - classes and a causative variant in the -ta/pa- classes, as illustrated by the data in (2) and (3).

\footnotetext{
auxiliary; COP copula; -DA- -da- verb class marker; DEF definite article; DS different-subject switch-reference marking; FUT future tense; IMPER imperative; INDEF indefinite article; INF infinitive; INTERR interrogative marker; IRR irrealis modality; IRREV marker of irreverence; NEG negative; NOM nominative case; NON-NOM nonnominative case; PA - $p a$ - verb class marker; PAST past tense; PL.EXCL plural exclusive (of first-person plural); PL.INCL plural inclusive (of first-person plural); PL plural; PRES present tense; PRFCT perfect aspect; RAUPI the Ulwa marker raupi (see 5); SENT.KA the sentential $k a$ marker in Ulwa (Koontz-Garboden 2007a); sING singular; ss same-subject switch-reference marking; TA -ta-verb class marker; TOP topic marker; wA - wa- verb class marker; 1,2,3 first-, second-, third-person agreement; $\langle>$ gloss inside angle brackets indicates glossed morpheme is an infix.

${ }^{3}$ There are a number of minor and irregular verb classes as well. These are laid out in Green (1999:chap. 7). I leave these aside here.
} 
(2a) Asna ya andih birh-d-ida. shirt DEF already tear-DA-3SING.PAST

'My shirt has already torn'. (notes, 985)

$\begin{array}{llllll}\text { (2b) Lîma } & d a m-k a & y a & \text { sipitnak } & \text { karak } & \text { alh-p-i } \\ \text { lime } & \text { sweet-ADJ } & \text { DEF } & \text { fingernail } & \text { with } & \text { pierce-PA-SS }\end{array}$

$$
\begin{array}{llll}
\hat{u}-k a-t a k & y a & b i r h-p-i & y a k-n a k a
\end{array}
$$

'With a fingernail, one must pierce, tear, and remove the skin of the sweet lime'. (dict)

(3a)

$\begin{array}{llll}\text { Il-w-ing } & \text { kau } & \text { atak } & y a \\ \text { ascend-wA-1SING.PRFCT } & \text { when } & \text { stairway } & \text { DEF } \\ \text { bah-w-ida. } & & & \\ \text { break-wA-3SING.PAST } & & & \end{array}$

'When I climbed up the stairway, it broke'. (dict)

(3b) Arak-ki-bus bah-t-ikda.

gun-〈1sING $\rangle$ break-TA-1SING.PAST

'I broke my gun'. (dict)

The data in (2) and (3) illustrate the fact that for the causative/inchoative alternation, the $-d a / w a$ - suffixes appear on inchoative variants, as in $(2 a)$ and $(3 a)$, while the $-t a / p a$ - suffixes appear on causative variants, as in $(2 b)$ and $(3 b)$. This much is uncontroversial, readily accepted by all who have previously examined the Ulwa facts, including Hale and colleagues (Hale and Salamanca 2002 and Hale and Keyser 2002) and those basing other discussions on their description (Juarros 2003 and Benedicto 2005). What exactly the lexical semantic and syntactic nature of Ulwa verb roots and the verb class morphology is such that this state of affairs holds, however, is much less clear. In this paper, which is based on new analysis and data collected during 12 months of fieldwork, I show, contra Hale and colleagues, that no uniform analysis in terms of a root's argument structure can be given to -ta/pa-. Instead, the function of these suffixes is simply to derive a verbal stem from a (precategorial) root. The - $d a / w a$ - suffixes, by contrast, at least with roots denoting change of state, are argued to effect an anticausative operation on the root they suffix to. This kind of analysis of Ulwa verb class morphology, I show, goes a long way toward explaining a number of previously poorly understood and previously undocumented facts about the lexical semantics, syntax, and morphology of verbs in these classes. While the main focus of this paper is on the proper description and analysis of the Ulwa 
verb classes, it also has consequences for the theoretical literature on argument structure in that a previous analysis of Ulwa, which does not capture the range of new facts discussed here, has been taken in support of a particular theoretical architecture (Hale and Keyser 2002).

I begin by discussing both background and sources of data drawn on in my work on Ulwa. I then move on to discuss previous work on Ulwa verb class morphology, laying out some of the main insights of this work alongside some of the problems of the analysis of the facts developed in it. This is followed by arguments for my own analysis of the Ulwa verb class suffixes. I then describe and analyze certain lexical semantic, syntactic, and morphological facts captured in the context of this analysis. Finally, I offer some concluding remarks.

2. Background and sources of data. Ulwa is an endangered Misumalpan language spoken by approximately 350 adults (Green 1999:17ff.) in the village of Karawala on Nicaragua's Atlantic coast. Although some linguistic work had been carried out on Ulwa around the early 1900s (see Green 1999:chap. 1 for a comprehensive review) it was Ken Hale, Tom Green, and their colleagues that began in the late 1980s to conduct more recent work on the language. To date, there have been several articles and chapters discussing the verbal morphology of the language (Hale and Salamanca 2002, Hale and Keyser 2002, and Koontz-Garboden 2006b), verb-chaining constructions in Ulwa and Misumalpan more generally (Hale 1991b; 1997), an overview paper considering the relationship of Ulwa to its sister language Mayangna (Benedicto and Hale 2000), a sketch grammar and dictionary (Green 1999), and several chapters of a recent dissertation examining adjectives and related grammatical features in detail (Koontz-Garboden 2007b). This work was all carried out in the context of the Ulwa Language Project, a grassroots language documentation project founded by members of the Ulwa speaking community of Karawala concerned about the loss of their language. ${ }^{4}$

The research on Ulwa reported in this paper draws on data from this previous work in addition to my own fieldwork. The bulk of this fieldwork was carried out over an 11-month period from August 2004-July 2005 during which time I was in residence in Karawala, working in a monolingual fashion (Everett 2001) under the auspices of the Ulwa Language Project. Another fieldtrip to Karawala was carried out in March 2006 to collect additional data. Thus, in addition to the rich dictionary and sketch grammar of Green (1999) and the analysis of Hale and others, I also draw on my own work on the lan-

\footnotetext{
${ }^{4}$ For a history of the Ulwa Language Project, see Green and Hale (1998), Green (1999:chap. 1), Hale (1991a; 2001), and Koontz-Garboden (2006a) for more recent activities of the project.
} 
guage, comprising well over 1,000 pages of notes, many of which are undergoing the process of integration with an electronic version of the Ulwa dictionary, made available to me by Tom Green (2004).

Thus, the Ulwa data in the discussion that follows come from several sources: (a) the Ulwa dictionary (Green 2004), (b) sentences constructed by Ulwa speakers upon request for an example sentence illustrating a particular lexeme, $(c)$ changes made by me to these naturally occurring examples in order to elicit a judgment on a slightly altered sentence, and $(d)$ naturally occurring examples overheard in the community. Sentences taken from the Ulwa dictionary (Green 2004) are annotated "dict," while those from my own fieldnotes are annotated "notes," along with a page number referencing the place in my notes where the example in question can be found.

3. Hale's previous work and an alternative analysis. As mentioned in the introduction, pioneering descriptive and theoretical work has been carried out on Ulwa verb class morphology by Ken Hale in collaboration with several colleagues, particularly Samuel Keyser and Danilo Salamanca (Hale and Salamanca 2002 and Hale and Keyser 2002). In this section, I outline some of the additional descriptive observations that have come out of this work alongside Hale and colleagues' proposed analysis. Along the way, I suggest an alternative analysis I believe to be supported by the additional data discussed in the sections following this one.

Among the numerous insightful observations about Ulwa verb class morphology made by Hale in his previous work (some already discussed in the introduction) is the fact that although - $d a$-alternates with - $p a$ - (2), and -wawith -ta- (3), as demonstrated by Hale and Salamanca (2002:43ff.), for these four classes, all possible patterns of alternation exist. There are - $d a$ - intransitives with transitive - $t a$ - counterparts and other $-d a$ - intransitives with transitive - $p a$ - counterparts. Similarly, some - $w a$ - verbs have transitive -tacounterparts while other - $w a$ - verbs have transitive - $p a$ - counterparts. These combinations are illustrated in (4)-(7).

(4) -da- intransitive with - $p a$ - transitive

(4a) Kuring abuk-d-ida.

canoe capsize-DA-3SING.PAST

'The canoe capsized'. (Hale and Salamanca 2002:41)

(4b) Kuring abuk-pa-h!

canoe capsize-PA-2SING.IMPER

'Turn the canoe over!' (Hale and Salamanca 2002:41) 
(5) - da- intransitive with $-t a$ - transitive

(5a) Yang bikiska balna kaupak nû-da-ring. 1SING child PL from hide-DA-1SING.IRR

'I will hide (myself) from the children'. (Hale and Salamanca 2002:45)

(5b) Yang lih-ki-wan man kaupak nû-ta-ring. 1 SING money-〈1SING $\rangle$ 2SING from hide-TA-1SING.IRR

'I will hide my money from you'. (Hale and Salamanca 2002:45)

(6) -wa-intransitive with - $p a$ - transitive

(6a) Balauh ya Kim yam-ka yam-ta-sa dai table DEF Kim good-ADJ make-TA-3SING.NEG PAST bahangh yam-ka sak-wa-sa. because good-ADJ stand-WA-3SING.NEG

'Because Kim did not construct the table well, it does not stand well'. (notes, 1020)

(6b) Yaka pan-ka ya yam-ka daya-p-i that stick-3SING DEF good-ADJ lean-PA-SS sak-pa-h. stand-PA-2SING.IMPER

'Stand that stick up at a good angle'. (dict)

(7) -wa- intransitive with $-t a$ - transitive

(7a) Baka-ki itukwâna ala-w-ida. child-1sING large grow-WA-3SING.PAST

'My child has grown large'. (Hale and Salamanca 2002:46)

(7b) Alas baka-ka yam-ka ala-t-ang. s/he child-3SING good-ADJ grow-TA-3SING.PRFCT

'She raised her child well'. (Hale and Salamanca 2002:46)

Another important empirical observation made by Hale and Salamanca (2002) is that some verbs fail to alternate; there are plenty of intransitive verbs in the $-d a$ - class in particular that do not have transitive counterparts, a fact illustrated by the data in (8) and (9). 


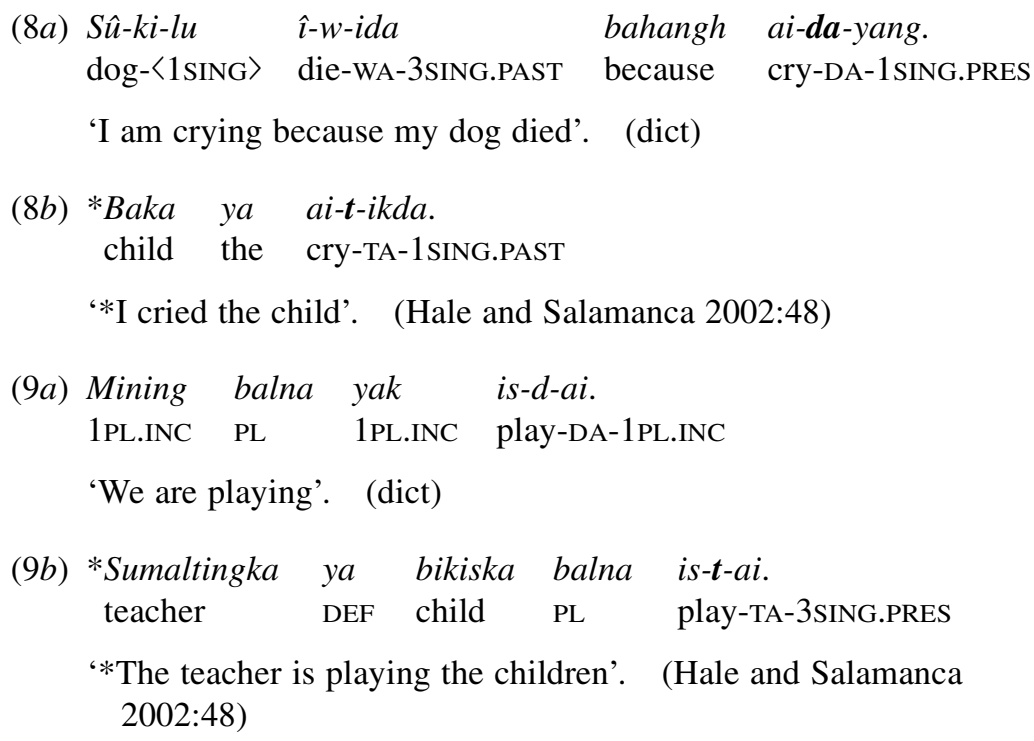

The fact that the causative/inchoative alternation is accomplished with all morphological combinations and that there are nonalternating intransitives in the $-d a$ - class leads Hale and Salamanca (2002:46ff.) to treat the major opposition in the Ulwa verb class system as one between - da/wa- and -ta/pa-, the former classes being intransitive and the latter transitive, consistent with the theory they lay out, whose major predictions in the realm of Ulwa verb class morphology are summarized in the following paragraphs. ${ }^{5}$

In various writings, particularly Hale and Salamanca (2002) and Hale and Keyser (2002:chap. 4), Hale and colleagues bring data like those discussed above to bear on Hale and Keyser's $(1998 ; 2002)$ theory of argument structure and try to make sense of them descriptively in light of this theory. The core idea of the theory Hale and his colleagues apply to Ulwa verb morphology is that verbal argument structure is a consequence of the lexical category of roots that verbs are constructed from. While adjectival roots project a specifier, nominal roots do not. The availability of this specifier is, for Hale and Keyser, a determinant of whether or not a verb, constructed from that root, takes a (direct) internal argument or not-unergatives, for example, which they analyze as denominal, do not, while unaccusatives, which they

\footnotetext{
${ }^{5}$ In none of his articles does Hale discuss whether there are nonalternating -wa-verbs. So far as I have been able to tell, there are some (e.g., nakawanaka 'to wound oneself'), though few. This may well be because there are far fewer -wa-verbs than - $d a$-verbs in the first place: 36 vs. 139 , by my rough count (see n. 37 ), in the Ulwa dictionary.
} 


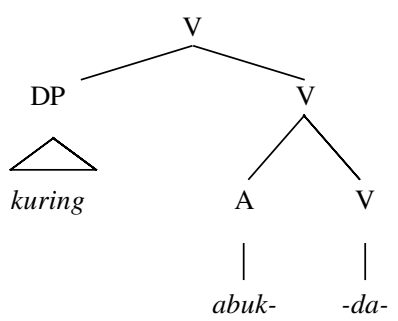

FIG. 1

analyze as deadjectival, do. All verbs, regardless of lexical category, are later merged with a higher IP. ${ }^{6}$

Hale and colleagues' analysis of Ulwa follows this general approach. ${ }^{7}$ Roots, like bah- 'break', birh- 'tear', auh- 'fat(ten)', etc., are treated as adjectival and, as a consequence, on their account, both causative and inchoative verbs can be constructed from these roots. On the Hale and Keyser theory, the root must first merge with a verbal head, with which it will "conflate," in order to project its specifier. This verbal head, Hale and Salamanca claim, in Ulwa is phonologically realized (via "late insertion," according to Hale and Keyser 2002:78, consistent with principles of Distributed Morphology) as $-d a$ - or $-w a$ - The sentence in (10), then, is analyzed by Hale and colleagues as in figure 1 (with the DP later moving to spec,IP for case-theoretic reasons on the Hale and Keyser theory).

(10) Kuring abuk-d-ida.

canoe capsize-DA-3SING.PAST

'The canoe capsized'. (Hale and Salamanca 2002:41)

In order to derive the causative version of 'capsize', the structure in figure 1 is merged with another "transitivizing" verbal head. Transitivizer is perhaps something of a misnomer for this verbal head, since it is not directly responsible on the Hale and Keyser theory for introducing the external argument. Instead, it is responsible for satisfying the Case requirements of the lower DP,

\footnotetext{
${ }^{6}$ The internal argument, if there is one, can in some cases raise to the spec,IP position, which is Hale and Keyser's analysis of the causative/inchoative alternation-in the causative variant, the spec,IP position is filled by an argument distinct from the internal argument, while in the inchoative, the internal argument has moved to the spec,IP position from the internal argument position, for case-theoretic reasons. See Hale and Keyser (2002:chap. 1).

${ }^{7}$ The analysis of Ulwa is laid out in most detail in Hale and Salamanca (2002). Even there, though, it is left vague in many respects. Drawing on both Hale and Keyser's (2002) general (non-Ulwa) discussion and the thoughts of an anonymous reviewer, I fill in the essential details with respect to Ulwa in what follows.
} 


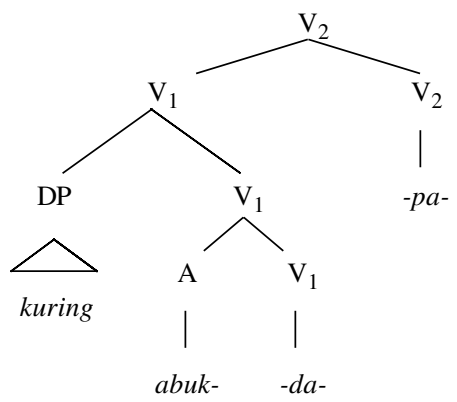

FIG. 2

preventing it from moving to the higher IP position in order to check Case (Hale and Keyser 2002:11 and Hale and Salamanca 2002:30). In this way another argument, the external argument, can be introduced. Thus, the second verbal head V2 is responsible for transitivization, albeit in an indirect way.

With this as background, the claim of Hale and Salamanca (2002:43) for causatives like (11) is that ". . . the structures [e.g., figure 2] . . are abstractions, representing just the syntactic relations involved. . . the root $\mathrm{R}$ conflates first with $\mathrm{V}_{[1]}$, the resulting complex conflates with $\mathrm{V}_{[2]}$, and the verbal heads are realized as the single suffix $-p a . " 8$ Although Hale and Salamanca are no more explicit about the conditions for appearance of the particular verb class markers than this, the idea seems to be (as suggested by an anonymous reviewer) that the appearance of the verb class markers - $p a$ - and - $t a$ is triggered by this conflation process. That is, it is not the case that the phonological material " $p a$ " appears under $\mathrm{V}_{2}$, but that this is inserted postsyntactically, its appearance conditioned by the presence of all of the conflated features that appear together in $\mathrm{V}_{2}$ at PF. The same view is suggested more generally by Hale and Keyser, who claim that "[vocabulary] items are inserted if they can be, in accordance with their allomorphy and contextual requirements; portmanteau morphemes exist as vocabulary items and are appropriately inserted into 'fused' positions available at S-Structure" (Hale and Keyser

\footnotetext{
${ }^{8}$ In the preceding quotation, I have changed the labeling in the original, from $\mathrm{V}_{1}$ to $\mathrm{V}_{2}$ and vice versa, for expository purposes. Also, although Hale and Salamanca (as evidenced in the same quotation) speak of Ulwa roots as category-less (as evidenced, e.g., by use of the term "the root R"), I have labeled them with category information, as in, e.g., figure 1, since it is, on their theory, a property of the syntactic category of the root whether a specifier is projected or not and, thus, whether a verb is transitive or intransitive. On their theory, adjectival roots force projection of a specifier, while nominal roots do not. In labeling the structure in this way, I am making no claim about what I believe to be the category of these roots; I am merely trying to accurately represent their theory.
} 
TABLE 1

Predictions of Hale and Salamanca's (2002) Analysis of

Ulwa Verb Class Morphology and Transitivity

\begin{tabular}{lcc}
\hline \hline & Intransitive & Transitive \\
\hline$-d a-$ & Yes & No \\
$-w a-$ & Yes & No \\
$-p a-$ & No & Yes \\
$-t a-$ & No & Yes \\
\hline
\end{tabular}

2002:78). This realizational approach to verbal morphology, it turns out, is crucial for their analysis of Ulwa causative verbs, since with a morphemebased approach stacking would be predicted by their claim that the root conflates with two verbal heads. The causative of 'capsize' in (11), for example, rather than abuk-pa-, would be predicted to be $a b u k-d a-p a-$, contrary to fact.

(11) Kuring abuk-pa-h!

canoe capsize-PA-2SING.IMPER

'Turn the canoe over!' (Hale and Salamanca 2002:41)

If we step back and take stock of Hale and colleagues' analysis, we see that it makes two predictions of interest here. First, $-d a / w a-$ appear only with intransitive verbs, spelling out the first verbal head with which the root merges (and subsequently conflates). Second, -ta/pa-, whose appearance is sanctioned in contexts where the first verbal head, the root, and the second verbal head are conflated together in $\mathrm{V}_{2}$, appear with transitive verbs. This must be so, since (with the realizational-based Distributed Morphology approach adopted by Hale and colleagues) -ta/pa-will appear only if there has been conflation into a second V head, which itself checks the Case of the internal DP (thereby preventing it from moving to IP). This, in turn, indirectly (but definitively) leads to a transitive structure. Thus, a prediction of their analysis is that -ta/pa- verbs are transitive, never intransitive. ${ }^{9}$ The predictions of Hale and Salamanca's analysis of the transitivity of verbs in the various Ulwa verb classes is summarized in table 1.

\footnotetext{
${ }^{9}$ An anonymous reviewer, by contrast, suggests that $-t a / p a$ - could appear with intransitive verbs using the Hale and Salamanca account (though they never suggest this), as follows: "V1 could, in principle, be merged directly to a root and that will predict there is no 'object.' The morphological output of V1 in that case could perfectly be an intransitive -ta- or -pa-verb." Direct merger with the root (and conflation with it) in the Hale and Salamanca analysis, however, as already seen, is the condition for realization of $-d a / w a-$ not -ta/pa-. One could, of course, stipulate another rule that would allow -ta/pa- realization as well under these circumstances. This, however, would require further stipulation for each root which verb class marker it appears with under merger and conflation with $\mathrm{V}_{1}$. This, in turn, reduces the whole question to root-specific stipulation of verb class markers, something Hale and Salamanca (2002:59) clearly hope to avoid.
} 
Further research, on which I report below, suggests that while Hale and colleagues' prediction that $-d a / w a$ - verbs are intransitive is indeed largely correct (though not without certain complications), it is not the case that -ta/pa-verbs are always transitive, a finding which argues against the Hale and Salamanca treatment of it. ${ }^{10}$ This finding, among others highlighted below, calls into question their analysis of the -ta- and - $p a$ - verb class markers.

The alternative I propose for $-t a / p a$ - is simply that they verbalize a nonverbal, possibly precategorial root, altering in no way its lexical semantics or argument structure. ${ }^{11}$ The lexical semantics of roots surfaces unaffected when suffixed by -ta/pa-. This finding regarding the nature of -ta/pa-forces a reconsideration of the nature of $-d a / w a-$. Unlike -ta/pa-, where I show that the facts are simply much more complicated than suggested by Hale and colleagues' discussions, I believe the basic facts of $-d a / w a-$, as previously stated, to be correct-they seem (with certain complications I discuss) to appear almost exclusively in intransitive constructions. There is more to be said, however, about how the intransitivity of $-d a / w a-$ verbs comes about, particularly with change-of-state verbs, where I suggest the function of these suffixes is that of an anticausativizer. ${ }^{12}$ I first discuss the facts of -ta/pa-, turning then to their implications for the analysis of $-d a / w a-$.

4. The -ta/pa- suffixes as verbalizers. In the sections that follow, I lay out the evidence that shows that contrary to the analysis of Hale and colleagues, -ta/pa- are not responsible for the transitivity of roots they suffix to. Further, I show that they in fact do not alter the meaning of the root in any way. Instead, they simply turn a root into a verbal stem, allowing the root's meaning to surface unaltered. The arguments for this come from patterns of verbal alternations, morphosyntactic encoding of the arguments of these verbs, and from the kinds of events encoded by verbs in these classes.

${ }^{10}$ Hale and Salamanca (2002:49) seem to recognize that there exist intransitive -ta/pa-verbs, highlighting this as an area in need of further study. Nevertheless, as discussed above, their analysis predicts their nonexistence.

${ }^{11}$ My own view is that argument structure follows from lexical semantics, as in the work of Pinker (1989), Levin and Rappaport Hovav (1995), Wunderlich (1997), and others. So, while I refer in the remainder of the paper to -ta/pa-not altering the lexical semantics of the root, a consequence of this is also that the argument structure lexically specified in the root is also not altered by $-t a / p a-$.

${ }^{12}$ This treatment of $-d a / w a$ - is akin to what Hale and Keyser (1998) propose for break-type verbs in O'odham, based on their observation that the causative is marked (with a reflexive morpheme) relative to the inchoative from which it is derived. I suspect, then, that this kind of proposal could be implemented in their framework. As already stated, the analysis of -ta/pa- is what is more problematic. 
4.1. The heterogeneous transitivity of $-\mathbf{t a} / \mathbf{p a}$ - verbs. Among the most important empirical observations for the study of transitivity and Ulwa verb classes to emerge from recent work is the finding that there are a host of intransitive verbs in the $-t a / p a$ - classes. Further, in addition to having intransitive uses, many of these, such as those in (12)-(14), fail to have transitive uses. $^{13}$

(12a)

\begin{tabular}{|c|c|c|c|}
\hline $\begin{array}{l}\text { Baka-ki } \\
\text { child-1SING }\end{array}$ & $\begin{array}{l}\text { al } \\
\text { male }\end{array}$ & $\begin{array}{l}\text { andih } \\
\text { already }\end{array}$ & $\begin{array}{l}\text { bata-p-ai } \\
\text { man-PA-3SING.PRES }\end{array}$ \\
\hline $\begin{array}{l}\text { bahangh } \\
\text { because }\end{array}$ & $\begin{array}{l}\text { tuk-ka } \\
\text { work-3SING }\end{array}$ & $\begin{array}{l}t \hat{\imath}-k a \\
\text { heavy-ADJ }\end{array}$ & $\begin{array}{l}\text { yam-t-i } \\
\text { do-TA-SS }\end{array}$ \\
\hline
\end{tabular}

1SING.NON-NOM-give-3SING.PRES

'Since my son is fast becoming a man he does the heavy work for me'. (dict)

(12b) *Yang (raupi) baka-ki al ya bata-p-uting.

$1 \mathrm{SING}$ (RAUPI) child-1SING male DEF man-PA-1SING.FUT

'I will raise my son into a man'. (notes, 474)

(13a) Was isau lau-t-ida bahangh wassik ya

water much fall-TA-3SING.PAST because river DEF

amat-p-ida.

swell-PA-3SING.PAST

'Because it rained a lot, the river swelled'. (notes, 989)

(13b) *Alah was baka ya amat-p-ida.

God water small DEF swell-PA-3SING.PAST

'God swelled the stream'. (notes, 459)

(14a) Turuh auh-ka balna tipit-t-ai.

cow fat-ADJ PL congeal-TA-3SING

'The fat of the cow congeals'. (notes, 969)

(14b) *Turuh auh-ka ya tipit-t-uting. cow fat-ADJ DEF congeal-TA-3SING.FUT

'I'm going to congeal the fat of the cow'. (notes, 969)

There are other intransitive -ta/pa-verbs that do have transitive counterparts, as illustrated in (15) and (16).

${ }^{13}$ There are many -ta/pa-verbs, by contrast, that have both transitive and intransitive uses. The verbs in (15) and (16) are examples. 
(15a) Bâwas, tining karak yak wat-ya kau, diarrhea vomit with 1PL.INCL catch-3SING.PRES when mâ bû datak mikdini ya andih day two after eye.1PL.INCL DEF already puruh-t-ai. deep.TA.3SING.PRES

'After two days of diarrhea and vomiting our eyes are already sunken'. (dict)

(15b) Yang nuh-ki ya kanas puruh-ta-yang, 1SING mortar-1SING DEF more deep-TA-1SING.PRES

$\begin{array}{llllll}\text { pihmak } & \text { ya } & \text { kanas } & \text { isau } & \text { wat-rang } & \text { yulka. } \\ \text { rice } & \text { DEF } & \text { more } & \text { much } & \text { fit-3SING.IRR } & \text { so.that }\end{array}$

'I'm deepening my mortar so it will hold more rice'. (dict)

$\begin{array}{lllll}\text { (16a) Kasnaka } & d \hat{\imath}-k a & \text { mah-ka } & \text { kas-ring } & \text { laih } \\ \text { food } & \text { thing-3SING } & \text { much-ADJ } & \text { eat-3SING.IRR } & \text { if }\end{array}$ auh-ta-ring.

fat-TA-1SING.IRR

'If I eat a lot I will become fat'. (dict)

(16b) $S \hat{u}-k i-l u \quad a u h-t-i k d a$.

dog-〈1sING $\rangle$ fat-TA-1SING.PAST

'I fattened my dog up'. (notes, 968)

Alternating verbs, i.e., verbs having both a transitive and intransitive variant, like the ones illustrated in (15) and (16), are different from other alternating pairs, like those in (2) and (3)-repeated in (17) and (18), in that there is no change in verb class associated with the change in valence.

(17a) Asna ya andih birh-d-ida.

shirt DEF already tear-DA-3SING.PAST

'My shirt has already torn'. (notes, 985)

(17b) Lîma dam-ka ya sipitnak karak alh-p-i lime sweet-ADJ DEF fingernail with pierce-PA-SS $\begin{array}{llll}\hat{u} \text {-ka-tak } & y a & \text { birh-p-i } & \text { yak-naka. } \\ \text { skin-〈3SING }\rangle & \text { DEF } & \text { tear-PA-SS } & \text { remove-3SING.INF }\end{array}$

'With a fingernail, one must pierce, tear, and remove the skin of the sweet lime'. (dict) 
(18a)

$\begin{array}{llll}\text { Il-w-ing } & k a u & a t a k & y a \\ \text { ascend-WA-1SING.PRFCT } & \text { when } & \text { stairway } & \text { DEF } \\ \text { bah-w-ida. } & & & \\ \text { break-WA-3SING.PAST } & & & \end{array}$

'When I climbed up the stairway, it broke'. (dict)

(18b) Arak-ki-bus bah-t-ikda.

gun-〈1SING $\rangle$ break-TA-1SING.PAST

'I broke my gun'. (dict)

Additional examples of -ta/pa- intransitives are given in (19) and (20). ${ }^{14}$

(19) Intransitive change-of-state verbs in -ta-class (dict and fieldnotes) auhnaka 'become fat'; buhnaka 'become dry (e.g., clothes)'; dutnaka 'spoil/rot'; lalahnaka 'ripen, rot'; lapusnaka 'be/become baggy/sag'; pakapnaka 'stiffen, become rigid'; pânaka 'grow'; paunaka 'turn red'; pinaka 'become blind, dry up (eyes)'; pulunaka 'flower, blossom'; pupuhnaka 'swell'; puruhnaka 'become sunken (cheeks, eyes)'; putnaka 'billow (smoke)'; ripnaka 'cool off '; bangnaka 'to become full'; damnaka 'to sweeten'; sapaknaka 'sour, ferment, spoil'; siunaka 'be fully developed but not ripe'; tapalhnaka 'spoil, become bitter'; tipitnaka 'congeal, coagulate, harden'; tubaknaka 'become thick/overgrown (e.g., trees)'; wirunaka 'shrivel, dry out (green, unripe fruit)'; nanaknaka 'curdle'; pulingnaka 'blister'

(20) Intransitive change-of-state verbs in - pa-class (dict and fieldnotes) ingnaka 'to become light/light up'; baknaka 'to rot, perish, get/be drunk'; wanihnaka 'to become pregnant again'; babarnaka 'become thin'; amatnaka 'swell (river)'; batanaka 'become a man'; rukuhnaka 'become bumpy/break out in hives'; tutuhnaka 'become bumpy/break out in hives'; lusuhnaka 'become flaky'; lamnaka 'calm (e.g., body of water)'; lamatnaka 'swell (water)'; dalaunaka 'become gooey'; rainaka 'form slick on water'; aisaunaka 'disappear'; buhutnaka 'become cloudy'; barahnaka 'burn partially/incompletely'; minisihnaka 'become dirty'; tînaka 'become rusty/get out of practice'; disnaka 'become silent, quiet down'; dasinaka 'become strong'; wasaknaka 'become tangled, become embroiled in a fight'; lilisnaka 'become tattered, ragged'; witnaka 'become used

\footnotetext{
${ }^{14}$ Some of the verbs listed in (19) and (20) also have transitive uses. I have not yet been able to systematically check one by one which of the verbs this holds true of and which it does not. I believe this is a tangential issue. Important for the matter at hand is simply the fact that they have intransitive uses.
} 
up'; tatasnaka 'get dirty'; ahaunaka 'loosen, become loose'; raunaka 'ripen, but not fully, just before softening'; bisinaka 'shrink by losing some'

The fact that so many -ta/pa- verbs are intransitive argues against Hale and colleagues' analysis of -ta/pa- outlined above. Equally important is that in addition to alternating transitive -ta/pa- verbs and nonalternating intransitive -ta/pa-verbs, there are also nonalternating transitive -ta/pa-vebs, i.e., transitive verbs in the -ta/pa- classes that fail to have an intransitive - $d a / w a-$ alternate. Although I have yet to compile a comprehensive list of such verbs, some examples are given in (21). ${ }^{15}$

(21) Nonalternating transitive $-t a / p a-$ verbs

(21a) Kim raudi yal as kau mâdi bau-t-ida.

Kim RAUPI woman one at now hit-TA-3SING.PAST

'Kim just now hit a woman'. (notes, 1024)

(21b) Al ya yâ-ka-mak tus-p-ai.

man the farm-〈3SING〉 chop-PA-3SING.PRES

'The man is chopping (= clearing in a chopping manner) his farmland'. (dict)

(21c) Yalau lalah-ka ya isau suyu-pa-yang.

mango yellow-ADJ the much like-PA-1SING.PRES

'I very much like ripe mangoes'. (notes, 1026)

Similarly, all of the verbs in the small set of ditransitive verbs listed by Green (1999:114) are in -ta/pa-, with not a single one in -da/wa-, as shown in (22). ${ }^{16}$

${ }^{15}$ The examples given in (21) are with verbs for which no intransitive use, be it in -da/waor -ta/pa-, is attested.

${ }^{16}$ To the best of my knowledge, Green's list of ditransitives is exhaustive. One possible addition might be punnaka, which is glossed in the dictionary as 'to heap, to pile, to load', but which often takes three arguments, as in $(i)$ :

(i) $\hat{U}$ kang-ka bahangh yang kasniki dî-ka balna ya $\hat{u}$ house full-ADJ because 1 SING food thing-3SING PL the house

wâk kau pû-t-ikda.

other in put-TA-1SING.PAST

'Because the house is full I put/piled the tableware in the other house'. (notes, 409)

The question is whether the kau-marked NP, $\hat{u}$ wâk, is a subcategorized argument or not, since kau is used in the language to mark both the (subcategorized) dative argument in ditransitives (e.g., 23) and also nonsubcategorized arguments, e.g., locatives (as illustrated by the example in n. 21). 
(22) Ditransitive verbs in Ulwa (Green 1999:114)

ânaka 'to give, to put'; kuinaka 'to ask for'; sirhnaka 'to lend'; sirahnaka 'to rent'; yaihnaka 'to bring near'

There are no $-d a / w a$ - counterparts of these verbs, and to the best of my knowledge, they are exclusively ditransitive, though I have not carried out a systematic examination of this question. ${ }^{17}$ The important point, however, is that they are three-argument verbs, as exemplified for anaka 'to give, to put' and kuinaka 'to ask for' in (23).

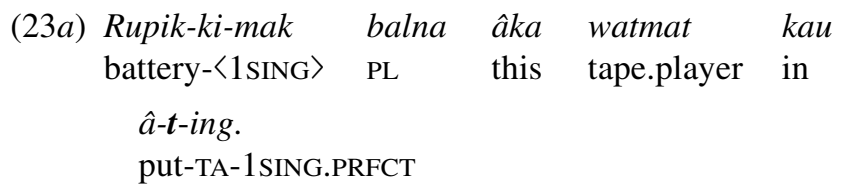

'I put my batteries in the tape player'. (dict)

\begin{tabular}{|c|c|c|c|c|c|c|}
\hline $\begin{array}{l}\text { Yang } \\
\text { 1SING }\end{array}$ & kahlu & yam-ka & as & tal-ikda & lau & \\
\hline & & & kau & $\boldsymbol{t}$-uting. & & \\
\hline NG & not & SING & from & k.fol & FUT & \\
\hline
\end{tabular}

'I am going to ask my mother for the nice shirt I saw sitting there'. (dict)

The patterns of transitivity found among the -ta/pa- verbs, then, are quite varied. These are summarized in (24).

(24a) Alternating -ta/pa- with intransitive variant in -da/wa- (e.g., bahnaka/bahwanaka 'to break')

(24b) Alternating -ta/pa- with intransitive variant in -ta/pa- (e.g., auhnaka 'to become fat')

(24c) Nonalternating -ta/pa- intransitive (e.g., pânaka 'to sprout')

(24d) Nonalternating -ta/pa- transitive (e.g., baunaka 'to hit')

(24e) Ditransitive -ta/pa- (e.g., ânaka 'to give')

The kind of heterogeneity summarized in (24) is not consistent with -ta/pahaving a uniform outcome on the argument structure of roots to which they suffix, contra Hale and colleagues. Instead, I believe this heterogeneity suggests that the variation found among -ta/pa-class verbs is located in the lexical entries of each individual root and that $-t a / p a-$ merely serve to turn these

\footnotetext{
${ }^{17}$ There is one caveat to this statement, which is that the verb ânaka 'to give' has a separate, if related sense, meaning something like 'to cause', and is used extensively in the periphrastic causative construction, as discussed by Hale $(1991 b ; 1997)$. Still, there is no use of anaka with the sense 'to give, to put' that is not ditransitive.
} 
bound roots into verbal stems whose argument structure is a consequence of the meaning of the root. Additional evidence for this position comes from the fact that there is even greater heterogeneity among -ta/pa- verbs than revealed by (24), as discussed in the following section.

4.2. Impersonal verbs. Ulwa has two distinct classes of intransitive verbs: $(a)$ intransitive verbs whose single argument looks as though it is a subject, and $(b)$ intransitive verbs whose single argument looks as though it is NOT a subject. ${ }^{18}$ The existence of these two separate classes has not been previously recognized in investigations of Ulwa verb morphosyntax (Hale and Keyser 1998, Green 1999, Hale and Salamanca 2002, Hale and Keyser 2002, and Juarros 2003) (though it has indeed been briefly recognized in the description of Mayangna verb classes given by Norwood 1997:46 and is under investigation by Charles and Torrez [forthcoming]). As is shown in the discussion that follows, the fact that they $(a)$ exist and $(b)$ fall into the morphological verb classes they do offers further evidence for the view presented here that $-t a / p a$ - perform no uniform semantic function on roots,

\footnotetext{
${ }^{18}$ These verbs in Ulwa seem to have a profile similar to what have been called in some Australian languages "impersonal verbs" (Walsh 1987 and Evans 2004), a term I adopt here for the Ulwa verbs under investigation. An anonymous reviewer suggests that these verbs are psych verbs, of the kind discussed by Belletti and Rizzi (1988). While this seems plausible for some of the verbs, particularly for those that take a human argument (e.g., dalanaka 'to be in pain', suhnaka 'to become tired', nananaka 'to tremble'), it seems to me less plausible for those that do not (e.g., pânaka 'to grow', siunaka 'to become ripe', kipnaka 'to flow quickly (of water)', etc.). While the former might arguably be two-argument verbs, like the verbs examined by Belletti and Rizzi (1988), as shown by the example for dalanaka 'strengthen' in (i) — where more analysis might reveal that both mining muihni balna 'our bodies' and yak 'us (inclusive)' are subcategorized arguments, it seems less plausible that there is any more than one argument for verbs like pânaka 'grow' in (ii).
}

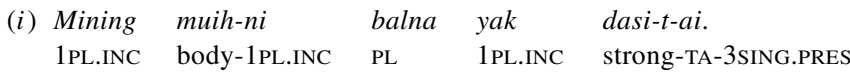

'Our bodies are strengthening'. (notes, 1083)

(ii) Yâkalah tal-yang pan sik-ka balna isau pâ-t-ang lau that.one see-1SING tree big-ADJ PL many grow-TA-3SING.PRFCT sit $\begin{array}{ll}\text { lau } & k a . \\ \text { sit } & \text { SENT.KA }\end{array}$

'On that one (=page), I see many big grown trees sitting there'. (notes, 1092; naturally occurring in telling of Mercer Mayer's Frog Story)

This issue merits further investigation, and what I have to say on the matter should be taken as the first attempt to raise the issue, which (as noted below) has not figured at all in previous discussions of Ulwa verb class morphology. I hope that the work presently being conducted on this topic by Charles and Torrez (forthcoming) will shed light on these issues, at least in Mayangna. 
TABLE 2

UlWA Pronouns

\begin{tabular}{llc}
\hline \hline & Nominative & Nonnominative \\
\hline 1 sing & yang & yâ \\
2 sing & man & mâa \\
3 sing & alas & alas \\
$1 \mathrm{pl} . \mathrm{excl}$ & yangna & yâna \\
$1 \mathrm{pl}$.incl & mining & yak \\
$2 \mathrm{pl}$ & manna & mâna \\
$3 \mathrm{pl}$ & alas balna & alas balna \\
\hline
\end{tabular}

instead simply turning them into verbal stems. The observation is that it is not only the case that intransitive verbs are found in the -ta/pa-classes, but that these intransitive verbs themselves do not form a homogeneous class, there being both impersonal and nonimpersonal intransitive verbs in -ta/pa-. By contrast, in $-d a / w a$ - it seems to be the case that most intransitive verbs are not impersonal, though further descriptive work is needed.

First, I lay out the facts, beginning with a description of verbs whose single argument behaves as though it is a subject, followed by a discussion of verbs whose single argument behaves as though it is not a subject. For both classes, I examine the behavior of the verbs on three diagnostics that distinguish the two classes: (a) pronominal case, $(b)$ subject/verb agreement, and $(c)$ switch-reference marking in verb-chaining constructions.

4.2.1. Verbs whose single argument behaves as a subject. The first group of intransitive verbs are those in which the single argument is treated, according to the three diagnostics under examination, as a subject. The first of these diagnostics is case in the pronominal system. Although Ulwa does not overtly mark case on nominals, there is a nominative/nonnominative distinction in first- and second-person pronouns. This is laid out in table 2.

For intransitive verbs in the class where the single argument is subjectlike, when they take a first- or second-person pronominal as their argument, the pronominal is nominative, as shown by the data in (25).

(25a) Yang tuh-p-ikda.

1SING.NOM spit-PA-1SING.PAST

'I spat'. (notes, 1135)

(25b) Yang sînak kas-i bât-p-ikda.

1SING.NOM bean eat-ss fart-PA-1sING.PAST

'I ate beans and farted'. (notes, 1063) 


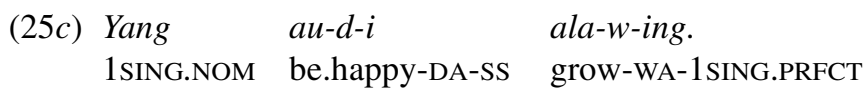

'I grew up happy'. (notes, 1079)

It is also the case that verbs in this class agree in person and number with their argument, as is expected of subjects on the basis of their behavior with transitive verbs. This fact is also illustrated by the data in (25).

The final diagnostic I examine for subjecthood of the single argument of this class of intransitives comes from switch reference. In Ulwa, verbs can be chained together in coordinate-like (sometimes serial verb-like) constructions, with the first verb being marked for whether or not it has the same subject as the following verb (Hale 1991b; 1997). When intransitive verbs in the class under discussion are chained together with a verb that shares the same logical subject, the first verb shows same-subject morphological marking, as expected, rather than different-subject morphological marking. This state of affairs, illustrated in (26)-(28), is what is expected if the argument of the intransitive is indeed a subject.

(26a) Alas balna asal-d-i luk-di-dida.

s/he PL embarrass-DA-SS hide-DA-3PL.PAST

'They became embarrassed and hid'. (notes, 1122)

(26b) *Alas balna asal-da-dak luk-di-dida. s/he PL embarrass-DA-3PL.DS hide-DA-3PL.PAST

'They became embarrassed and hid'. (under coreferent interpretation; notes, 1122)

(27a) Wahai-ki kal dak-t-i naka-w-ida. brother-1SING self cut-TA-SS wound-WA-3SING.PAST

'My brother cut and wounded himself'. (notes, 1071)

(27b) *Wahai-ki kal dak-t-ak naka-w-ida. brother-1SING self cut-TA-3SING.DS wound-WA-3SING.PAST

'My brother cut and wounded himself'. (under coreferent interpretation; notes, 1071)

(28a) Was ya lau-t-i lâ-t-ida.

rain DEF fall-TA-SS pass-TA-3SING.PAST

'The rain fell and passed'. (notes, 1079) 
$\begin{array}{rlll}(28 b) * W a s & y a & l a u-t-a k & l \hat{a}-t-i d a . \\ \text { rain } & \text { DEF } & \text { fall-TA-3SING.DS } & \text { pass-TA-3SING.PAST }\end{array}$

'The rain fell and passed'. (under coreferent interpretation; notes, 1079)

In sum, then, there is a class of intransitive verbs whose single argument behaves as a subject according to three diagnostics: subject/verb agreement, pronominal case, and switch reference. Some of the intransitive verbs in this class are given in (29).

(29) Some intransitive verbs whose single argument behaves as a subject bâtnaka 'to fart'; baknaka 'to become drunk' (also has a variant with impersonal behavior meaning 'dead'); minisihnaka 'to get dirty'; tuhnaka 'to spit'; asaldanaka 'to become embarrassed'; alawanaka 'to grow up'; nakawanaka 'to wound oneself'; patdanaka 'to explode'; papdanaka 'to open'; lâwanaka 'to pass'; îranaka 'to run'; nanadanaka 'to shake'; ilwanaka 'to go up'

A point that I return to later in the discussion is that there are intransitive verbs of this type represented in all four morphological verb classes in the language, $-t a / p a$ - and $-d a / w a-$. For - $t a$ - and - $p a$ - class intransitives, however, it is not the case that all verbs in these classes that take only one argument treat their single argument in this way.

4.2.2. Impersonal intransitive verbs. According to the three diagnostics outlined in the previous section, there is a class of intransitive verbs that behaves quite differently from the one previously illustrated.

First, when predicated of a first or second person, with impersonal verbs case is nonnominative rather than nominative, in contrast to the case assignment for the single argument of verbs in the previous class. ${ }^{19}$ This is illustrated in (30)-(32).

$\begin{array}{lll}\text { (30a) } Y \hat{a} & \text { suh-p-ang } \\ & \text { 1SING.NON-NOM } & \text { tire-PA-3SING.PRFCT }\end{array}$

'I am tired'. (notes, mar06-10)

\footnotetext{
${ }^{19}$ Norwood (1997:46) claims that in the sister language Mayangna, the single argument of verbs in this class is dative. I leave as an open question whether it is dative or accusative in Ulwa. All that matters for the purposes of the discussion that follows is that there are two classes of intransitive that treat their single argument in significantly different ways-one as a subject, one not as a subject.
} 
(30b) Mâ daih-ka, yapa bahangh yâna

sun hot-ADJ that because 1PL.EXCL

suh-p-ang

tire-PA-3SING.PRFCT

'We (excl) are tired because of the hot sun'. (notes, 1054)

(31) Yang yab-ikda bahangh yâ

1 SING be.scared-1SING.PAST because 1SING.NON-NOM

nana-p-ida

tremble-PA-3SING.PAST

'I trembled because I got scared'. (notes, 1091)

(32) Yâ

baham-p-ai.

1SING.NON-NOM be.hungover-PA-3SING.PRES

'I'm hungover'. (dict)

The data in (31) and (32), which illustrate facts about case marking with impersonal verbs, also illustrate a contrast in subject/verb agreement when compared to the facts of agreement with nonimpersonal verbs, as discussed in the previous section. Whereas a nonimpersonal verb agrees with its single argument in person and number, as seen in (25), this is not the case for impersonal verbs, where the verb does not agree with its argument in person and number, as shown in (30)-(32) (with $30 b$ illustrating number disagreement).

It turns out that many impersonal verbs have meanings such that they do not occur with first- or second-person arguments. For these kinds of verbs, although the consequences for case cannot be observed (due to the lack of nominative/nonnominative contrast in the third-person cells of the pronominal paradigm, as seen in table 2), consequences for subject/verb agreement are still evident, as the verb exhibits singular agreement even with a plural subject, as shown by the naturally occurring example in (33).

(33) Mikdiki bûpak pî-t-ang. eye.1SING both blind-TA-3SING.PRFCT

'Both of my eyes have become blind'. (naturally occurring; 6/4/2005)

The same observation can be made for the verb pânaka 'grow' in (34a), where, when pushed, a consultant even denied the existence of a third plural form of the verb, as shown in (34b). 
(34a) Anu-ki pan-ka balna ya pâ-t-ai coconut-1SING tree-3SING PL DEF grow-TA-3SING.PRES

'My coconut trees are growing'. (notes, 1067)

(34b) *pâ-dai

grow-3PL.PRES

(judged to be nonexistent; notes, 1067)

Similarly, the sentence in $(35 a)$, constructed by me with third plural agreement, was corrected by a consultant to $(35 b)$, with third singular agreement, despite the plural subject.

$\begin{array}{lll}(35 a) * \text { Kal-ki } & \text { balna } & \text { dala-dai. } \\ \text { foot-1SING } & \text { PL } & \text { hurt-3PL.PRES }\end{array}$

'My feet hurt'. (notes, 1097)

(35b) Kal-ki balna dala-p-ai.

foot-1SING PL hurt-PA-3SING.PRES

'My feet hurt'. (notes, 1097)

Finally, with the impersonal verbs, even though a verb-chaining construction may conceptually seem to have the same underlying subject, differentsubject morphology can be used, as shown by the data in (36)-(38).

(36) $Y \hat{a}$

$$
\text { suh-p-ak dâ-p-ing. }
$$

1SING.NON-NOM tire-PA-3SING.DS leave-PA-1SING.PRFCT

'I got sick and tired of it and left it'. (naturally occurring; notes, 1100)

(37) Sû-ki-tak ya siu-t-ak kat walang gourd-〈1sING $\rangle$ DEF be.almost-ripe-TA-DS when fat

baka.

little

'When my gourd is almost ripe, it will be a little bit fat'. (notes, 486)

(38) Wahai-ki nana-p-ak wauh-d-ida.

brother-1SING tremble-PA-3SING.DS fall-DA-3SING.PAST

'My brother trembled and fell'. (notes, 1077) 
The fact that different-subject marking is used on the first verb in the verbchaining construction in sentences with impersonal verbs, such as the ones in (36)-(38), suggests that the two verbs do not share the same subject, despite the fact that the referent of this argument serves conceptually as the subject of each of these clauses. This makes sense if the single argument has a different grammatical status for the impersonal verb than it does for the nonimpersonal verb. ${ }^{20}$

These "impersonal" (intransitive) verbs, then, differ from their nonimpersonal counterparts on the basis of three diagnostics-pronominal case, subject/verb agreement, and behavior in verb-chaining constructions. A list of verbs for which at least one of these characteristic behaviors in the three constructions has been documented is given in (39).

(39) Some intransitive verbs displaying some or all of the impersonal verb properties

bahamnaka 'to be hungover'; dalanaka 'to be in pain'; pinaka 'to be(come) blind'; makauhnaka 'to be(come) tired'; raunaka 'become ripe, fruit'; minisihnaka 'become dirty' (also has nonimpersonal variant); lilisnaka 'become tattered' (also has nonimpersonal variant); buhnaka 'become dry'; dutnaka 'spoil'; baknaka 'spoil, drunk' (also has nonimpersonal variant; as impersonal, 'dead'); siunaka 'ripe, fruit' (also has nonimpersonal variant); lalahnaka 'become ripe'; pânaka 'grow'; suhnaka 'tire'; walahnaka 'to sweat'; dasinaka 'to be(come) strong'; bulusnaka 'to become black (as result of cooking)'; sangnaka 'clear (water)'; ripnaka 'to be cold'; isinaka 'to shake'; nananaka 'to tremble'; pakapnaka 'become stiff'; kipnaka 'flow quickly (water)'; lulungnaka 'to become weak'

In contrast to the situation that was observed with the nonimpersonal intransitive verbs, which show up in all four morphological classes, I am aware of only one solid example of an impersonal verb that is NOT in the -pa- or -ta-

\footnotetext{
${ }^{20}$ The naturally occurring sentence in $(i)$ is one in which two impersonal verbs appear together in a verb-chaining construction.

(i) $Y \hat{a}$

1SING.NON-NOM cold-TA-3SING.DS 1SING.NON-NOM shudder-PA-3SING.PAST
}

The fact that the first verb appears with different-subject switch-reference marking, despite the fact that they share a single (nonsubject) argument, suggests that switch-reference marking is indeed sensitive to something like subjecthood in Ulwa-although the two verbs share the argument, for neither of them is it the subject, and therefore they do not share a "subject." 
classes. ${ }^{21}$ This shows that there is even more heterogeneity in the argument structure of $-t a / p a-$ verbs than evidenced in the previous section. There is nothing about -ta/pa- that makes it possible to predict how an intransitive verb will treat its single argument. Instead, this seems to be a property of the root itself. The observation, then, is that -ta/pa- verbs are so heterogeneous in terms of their argument structure that there is no single operation that -ta/pa- could be performing that would yield this outcome. Instead, these differences in the argument structure of -ta/pa- verbs, I believe, simply follow from the lexical specification of the roots themselves. What -ta/pa- do, then, is simply to turn these roots into verbal stems, leaving their argument structure unchanged. As I show in $\mathbf{6}$ below, additional semantic facts point to the same conclusion. First, however, I turn to the consequences of this analysis of $-t a / p a-$ for the analysis of $-d a / w a-$.

5. Consequences for the analysis of $-d a / w a-$. In the previous section I detailed evidence suggesting that the right analysis of -ta/pa-is one in which they do nothing to the lexical semantics or argument structure of the roots they suffix to. Instead, the evidence suggests that they simply derive verbal stems from precategorial roots, leaving the semantics and argument structure of the root unaltered. If correct, this analysis has certain consequences for the analysis of $-d a / w a$ - verbs that have -ta/pa- counterparts, e.g., pairs of verbs like the ones in (2) and (3), repeated in (40) and (41).

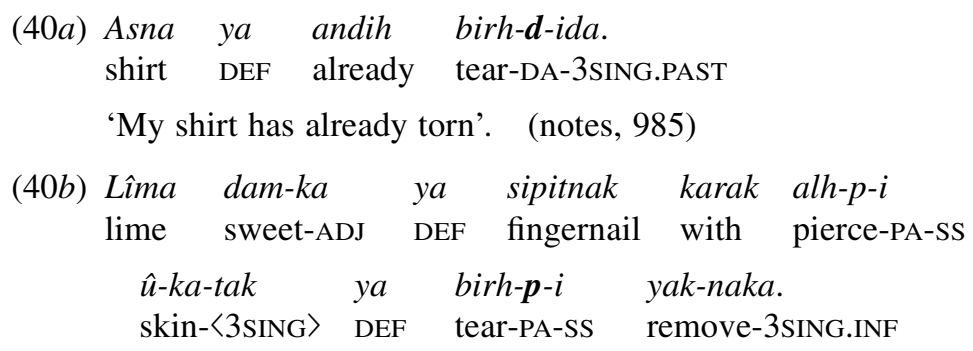

'With a fingernail, one must pierce, tear, and remove the skin of the sweet lime'. (dict)

\footnotetext{
${ }^{21}$ The verb is buihdanaka 'have a twitch or muscle spasm.' ( $i$ ) shows that the single direct argument of this verb is non-subject-like, in that the pronoun is nonnominative:

(i) Salah-ki takat kau mâ bû yapa yâ shoulder-1SING top on day two approximately 1SING.NON-NOM

buih-d-ai. twitch-DA-3SING.PRES
}

'I've been having muscle spasms in my shoulder for about two days now'. (dict) 
$\begin{array}{llll}\text { (41a) } \begin{array}{ll}\text { Il-w-ing } \\ \text { ascend-WA-1SING.PRFCT }\end{array} & \begin{array}{l}\text { kau } \\ \text { when }\end{array} & \begin{array}{l}\text { atak } \\ \text { stairway }\end{array} & \text { ya } \\ \text { Dah- } \boldsymbol{w} \text {-ida } & & & \\ \text { break-WA-3SING.PAST } & & & \end{array}$

'When I climbed up the stairway, it broke'. (dict)

(41b) Arak-ki-bus bah-t-ikda.

gun-〈1sING $\rangle$ break-TA-1SING.PAST

'I broke my gun'. (dict)

With the proposed analysis of -ta/pa-, roots like birh- in (40) and bah- in (41) are lexically transitive/causative, since they have transitive/causative meanings when used as -ta/pa-verbs. ${ }^{22}$ In order for the $-d a / w a$ - verbs based on these same roots in (40a) and (41a) to be intransitive, then, one of two situations must hold. One possibility is that roots are simply polysemous; in addition to the transitive/causative sense, they also have an intransitive/ inchoative sense that surfaces only in the presence of $-d a / w a-{ }^{23}$ Alternatively, it could be the case that $-d a / w a$ - alter the meaning of the root, deriving an inchoative verb from a causative. In other words, with this analysis $-d a / w a-$, at least with alternating roots, perform an anticausative function. ${ }^{24}$ The general direction of the literature on Ulwa verb classes, following from Hale and colleagues' work, has been to generate the different senses, causative and inchoative, from a single root meaning. While recognizing that it may be worth revisiting this particular assumption if more research becomes available, I follow the established tradition here and assume that causative and inchoative senses are derived from a single root meaning, in which case it must be that with alternating roots, $-d a / w a$ - perform an anticausativizing function.

So, the question to ask is whether there is any independent evidence that $-d a / w a$ - do indeed perform such a function. To a large degree, this depends on exactly how the anticausativization function is formalized, since there are a variety of ways of formalizing it, each with its own slightly different predictions (Koontz-Garboden 2009). Laying out arguments for and against

\footnotetext{
${ }^{22}$ This does not mean that intransitive $-t a / p a$ - versions of the same verbs are predicted not to exist. They do, and the analysis captures this fact. Since -ta/pa- do not alter the meaning or argument structure of the root, they allow any of possibly many senses of a single root to surface. This issue is discussed in detail in 6.2.

${ }^{23}$ With this kind of analysis, the verb class markers start to look much more like verbal classifiers found in certain Australian languages (Schultze-Berndt 2000).

${ }^{24}$ This is not to say that the anticausative function is performed by $-d a / w a-$ on all roots they suffix to. In fact, there is evidence that $-d a / w a$ - are middle voice markers. This issue goes beyond the scope of this paper, though it is broached again in $\mathbf{8}$.
} 
particular analyses of anticausativization is beyond the scope of this paper (though see Koontz-Garboden 2009). There is, nevertheless, at least one prediction that will be shared by any analysis of anticausativization which can be used as a preliminary test of the claim that $-d a / w a-$ serve this function. If $-d a / w a-$, with alternating roots, derive an intransitive inchoative verbal stem from a transitive/causative root, then it quite obviously must be the case that with alternating roots $-d a / w a-$ verbs are intransitive, and never transitive.

Intransitive uses of $-d a / w a$ - verbs with alternating roots are certainly the unmarked uses of such verbs, and indeed of $-d a / w a-$ verbs in general. The expected and unmarked pattern is illustrated in (42) from Green (1999:116) with the root $d \hat{a}-$ 'burn'. Green observes, as expected given what has been seen thus far, that while the -wa- class verb dâwanaka can be used intransitively, the -ta- class verb dânaka cannot.

$$
\begin{aligned}
& \text { (42a) } \hat{U} \text {-ki-tak dâ-w-ida. } \\
& \text { skin-〈1sING〉 burn-WA-3SING.PAST } \\
& \text { 'My skin burned'. (Green 1999:116) } \\
& \text { (42b) } * \hat{U} \text {-ki-tak dâ-t-ida. } \\
& \text { skin-〈1SING〉 burn-TA-3SING.PAST } \\
& \text { 'My skin burned'. (Green 1999:116) }
\end{aligned}
$$

Similarly, Green observes that with subjects like muih as 'somebody', while the -wa- class dâwanaka is unacceptable in transitive constructions, as shown in (43a), the -ta- class dânaka is indeed acceptable, as shown in $(43 b)$.

$\begin{array}{rlll}(43 a) * \text { Muih } & \text { as } & y \hat{a} & d \hat{a}-\boldsymbol{w} \text {-ida } \\ \text { person } & \text { INDEF } & \text { 1SING.NON-NOM } & \text { burn-WA-3SING.PAST }\end{array}$

'Someone burned me'. (Green 1999:116)

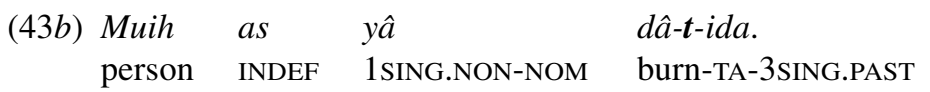

'Someone burned me'. (Green 1999:116)

The contrast in transitivity between the -wa- class dâwanaka and the -taclass dânaka observed in (42) and (43) is precisely what is expected on the basis of the observations in the previous sections. Green, however, also observes the data in (44).
(44a) Mâ daih-ka yâ
dâ-w-ida.
sun hot-ADJ 1SING.NON-NOM
burn-WA-3SING.PAST

'The sun burned me'. (Green 1999:116) 
(44b) Mâ daih-ka yâ

sun hot-ADJ 1SING.NON-NOM dâ-t-ida.

burn-TA-3SING.PAST

'The sun burned me'. (Green 1999:116)

According to Green, transitive uses, like (44a), of what are otherwise intransitive verbs are acceptable only when the "subject is the direct or 'physical' agent of the action (e.g., a force of nature)" (Green 1999:116) but not when "the subject acts of its own volition" (Green 1999:116). Thus, Green's claim is that while the sun is the direct physical cause of the burning event in (44a), this is not so with a person in (43a).

This phenomenon, Green writes, was discovered late in his studies on the language, and he gives only the example in (44) to illustrate the phenomenon, reporting that "though the phenomenon described here is robust and has been confirmed in several pairs of the dâwanaka/dânaka type, it is unclear how far-reaching its effects are" (Green 1999:116). Data from my more recent fieldwork confirm the judgments reported by Green in (42)-(44). Additional data I have collected, however, suggest that the situation is more complicated than Green's initial data suggested, and more certainly remains to be done on this issue.

The first complicating factor is that although all speakers I have consulted accept (44a), once one goes beyond the verb dâwanaka, judgments are less unanimous. Consider, for example, the root sah- 'crack/split', which has a transitive verbal stem in -ta- and an intransitive stem in - wa-. Although it is quite common in the village for objects like wood and coconuts to crack as a result of overexposure to the sun, and although it was observed in (44) that mâ daihka 'hot sun' can serve as a natural force subject with the -wa-class dâwanaka, with the verb sahwanaka 'to crack (intrans)', at least some speakers prefer the - $t a$ - version, as illustrated in (45). ${ }^{25}$

\footnotetext{
${ }^{25}$ In many of the examples that follow, the causer is followed by raupi, a particle whose functions are discussed at some length in Green (1999:110-12) and Koontz- Garboden (2007b:8691). I briefly summarize the function of interest here: raupi is the same subject form of a verb whose lexical meaning has been entirely bleached. Its function is to distinguish subject from nonsubject, particularly in contexts where it might be ambiguous which argument is the subject, for example, in cases where two verbal arguments carry the same person/number specifications. Even in cases where the person/number specifications differ, however, raupi (and raudi, the two seemingly being used interchangeably) can be used to mark the subject. Thus, alongside Green's example in $(44 b)$, for example, repeated in $(i a)$, the data in $(i b)$ are also attested:
}

(ia) Mâ daih-ka yâ dâ-t-ida.

sun hot-ADJ 1SING.NON-NOM burn-TA-3SING.PAST

'The sun burned me'. (Green 1999:116)

(ib) Mâ daih-ka raupi yâ dâ-t-ida.

sun hot-ADJ RAUPI 1SING.NON-NOM burn-TA-3sING.PAST

'The sun burned me'. (notes, mar06-60) 
(45a) Mâ daih-ka raupi sah-t-ida.

sun hot-ADJ RAUPI split-TA-3SING.PAST

'The hot sun split them (the coconuts)'. (notes, mar06-24)

(45b) *Mâ daih-ka raupi sah-w-ida.

sun hot-ADJ RAUPI split-WA-3SING.PAST

'The hot sun split them (the coconuts)'. (notes, mar06-24)

This is not universally the case, however, as a different speaker does accept the -wa-class sahwanaka in such a context, as shown in (46a), although it should be noted that in this context he originally supplied the - $t a$ - class version in (46b), stating upon questioning that he would also accept the $-w a$ class verb in $(46 a)$.

\begin{tabular}{|c|c|c|c|c|c|}
\hline$(46 a)$ & $\begin{array}{l}A n u-k i \\
\text { coconut-1SING }\end{array}$ & $\begin{array}{l}\text { pihtang } \\
\text { dried }\end{array}$ & $\begin{array}{l}\text { turu-p-ikda } \\
\text { shell-PA-1SING.PAST }\end{array}$ & $\begin{array}{l}\text { balna } \\
\text { PL }\end{array}$ & $\begin{array}{l}y a \\
\mathrm{DEF}\end{array}$ \\
\hline & $\begin{array}{ll}m \hat{a} & \text { daih-ka } \\
\text { sun } & \text { hot-ADJ }\end{array}$ & $\begin{array}{l}\text { raupi } \\
\text { RAUPI }\end{array}$ & $\begin{array}{l}\text { sah-wa-dida. } \\
\text { split-wA-3PL.PAST }\end{array}$ & & \\
\hline
\end{tabular}

'The hot sun split the dried coconuts that I had shelled'. (notes, mar06-20)

$\begin{array}{lllll}\text { (46b) } \begin{array}{llll}\text { Anu-ki } \\ \text { coconut-1SING }\end{array} & \begin{array}{l}\text { pihtang } \\ \text { dried }\end{array} & \begin{array}{l}\text { turu-p-ikda } \\ \text { shell-PA-1SING.PAST }\end{array} & \begin{array}{l}\text { PL } \\ \text { PLa }\end{array} & \begin{array}{l}\text { Da } \\ \text { DEF }\end{array} \\ \text { sun hot-ADJ } k & \text { raupi } & \text { RAh-t-ida. } & & \\ \end{array}$

'The hot sun split the dried coconuts that I had shelled'. (notes, mar06-20)

In addition to illustrating what appears to be variation in willingness to accept these kinds of natural force cause constructions, the data in (46) illustrate a second complicating factor. With Green's data in (44), the fact that the undergoer of the change of state is represented by a first-person singular pronominal while the verb agrees with the causer, mâ daihka 'the sun', suggests that the latter is indeed the subject. Nevertheless, I have found a number of examples in which the verb does indeed agree with the undergoer of the change of state, rather than with the natural force causer. This is the case with the -wa- class example in (46a), in contrast to its -ta-class counterpart in $(46 b) .{ }^{26}$ Another such example is given in (47).

\footnotetext{
${ }^{26}$ Data like those in (46a), and similar data below, call into question the description of raupi laid out in $\mathrm{n}$. 25. They show, in particular, that raupi, at least in some instances, does more (or less?) than simply mark the subject, since the verb agreement facts in (46a), for example, suggest that the argument marked by raupi is not, in fact, the subject. Data like these are discussed in Koontz-Garboden (2007b:89ff.), though further study is needed.
} 
(47a) Kasna yam-ka ya raupi tûruh baka-ka balna âka food good-ADJ the RAUPI cow child-3SING PL this ala-wa-dida. grow-WA-3PL.PAST

'Good food made the baby cows grow up'. (notes, 1056)
(47b) *Kasna yam-ka raupi tûruh baka-ka balna âka food good-ADJ RAUPI cow child-3SING PL this ala-w-ida. grow-WA-3SING.PAST

'Good food made the baby cows grow up'. (notes, 1056)

Again, the data in (47) show that the verb must agree with the undergoer of the change-of-state event named by the verb alawanaka 'to grow', as in $(47 a)$. It cannot agree with the raupi-marked causer, as shown by the data in $(47 b)$. In fact, this is the normal state of affairs in my data; the pattern observed by Green in $(44 a)$, where the $-d a / w a$ - verb unambiguously agrees with the causer, seems quite rare. ${ }^{27}$

Another complicating factor is that the same construction turns out to be used with nonalternating verbs, verbs which have no -ta/pa-counterpart and which, with the exception of the natural force construction, otherwise do not appear with a causer (unless in a periphrastic causative construction). Examples are given in (48)-(50).

$$
\begin{aligned}
& \begin{array}{lllll}
\text { Daih-ka } & \text { raudi } & \text { ama-ni-ki } & \text { wal-ta-sing, } & y \hat{a}-k a \\
\text { hot-ADJ } & \text { RAUPI } & \text { sleep-INF-1SING } & \text { want-TA-1SING.NEG } & \text { that }
\end{array} \\
& \text { dî-ka karak. } \\
& \text { thing-3SING with }
\end{aligned}
$$

'The heat makes it so that I do not want to sleep with that thing'. (speaker referring to a mosquito net; notes, 1102)

(49a) Nanghtak raupi isamh-da-yang. cold RAUPI sneeze-DA-1SING.PRES

'The/a cold made me sneeze'. (notes, 1043)

$\begin{array}{lll}\text { *Nanghtak } \quad y \hat{a} & i \text { samh-d-ai. } \\ \text { cold } & \text { 1SING.NON-NOM } & \text { sneeze-DA-3SING.PRES } \\ \text { 'The/a cold makes me sneeze'. } & \text { (notes, 1043) }\end{array}$

\footnotetext{
${ }^{27}$ The contexts in which such examples might occur are, nevertheless, not all that common, since much discourse deals with third-person singular entities acting on third-person singular entities, in which case it is impossible to tell whether the verb agrees with the causer or causee.
} 
(50a) Yabahna raupi sut-d-ikda. fear RAUPI jump-DA-1SING.PAST

'Fear made me jump'. (notes, 1045)

$\begin{array}{clll}(50 b) * \text { Yabahna } & \text { raupi } & y a & \text { sut-d-ida } \\ \text { Fear } & \text { RAUPI } & \text { 1SING.NON-NOM } & \text { jump-DA-1SING.PAST }\end{array}$

'Fear made me jump'. (notes, 1045)

In addition to showing that the natural force cause construction is found with verbs that do not alternate (there being no transitive use of amanaka 'sleep' and no -ta/pa- counterparts for isamhdanaka 'sneeze' and sutdanaka 'jump'), the data in (48)-(50) further illustrate the fact already illustrated above, that in this construction the verb generally agrees not with the natural force causer but with the argument naming the entity caused to undergo the event named by the verb. This is illustrated most clearly in (49) and (50): (49a) and $(50 a)$ are the acceptable versions where the verb agrees with the caused argument; in (49b) and (50b) the verb agrees with the natural force cause argument, and these forms are rejected.

All of this suggests that the situation with natural force causes and apparent transitive uses of $-d a / w a$ - verbs is much more complicated than initially believed and is in need of further study. First, there appears to be variation in the degree to which speakers allow the construction. Second, the nature of the construction itself also appears to be subject to variation, perhaps across speakers, but perhaps only across verbs, in terms of the degree to which the causer has "subject" properties; there are certainly data showing that in many instances the causer is not the subject. In these cases, it instead appears that this construction is simply a way of specifying the causer in some oblique way, perhaps not unlike the way in which causes with inchoative verbs in English (and other languages) can be specified with from, as illustrated in $(51) .^{28}$

(51) There was even an exceptionally good year when the branches of the tree almost broke from the weight of its own fruits. (Google)

It is also noteworthy that like the Ulwa natural force construction, English disallows agentive causes in this position, as evidenced by (52).

(52) *The branches of the tree broke from the lumberjack.

\footnotetext{
${ }^{28}$ See Alexiadou et al. (2006) for a good overview of data from several Indo-European languages. DeLancey (1984) discusses the same kind of data not only in English but in Hare (Athabaskan) and Newari (Tibeto-Burman) as well.
} 
It seems, then, that the kinds of facts observed here for Ulwa may well be better understood once they are situated in the context of the treatment of nonagentive causes more generally. The observation is that in other languages, nonagentive causes can be specified with otherwise intransitive verbs, so long as it is a particular kind of cause and so long as it is an oblique argument. Much work remains to be done on this topic, both in Ulwa and cross-linguistically; but in many of the cases discussed above, Green's original example standing as a glaring exception, there is reason to believe that the facts may be part of a more general cross-linguistic phenomenon that is not inconsistent with $-d a / w a$ - verbs being intransitive, at least no less intransitive than comparable verbs in other languages. ${ }^{29}$ On the basis of the available data, then, I think it would be premature to conclude that this construction seriously challenges the idea that the function of $-d a / w a-$ with alternating verb roots is that of an anticausativizer, particularly in light of the additional lexical semantic evidence adduced in $\mathbf{6}$ below. ${ }^{30}$

Although a formal analysis of auticausativization is beyond the scope of this paper (but see Koontz-Garboden 2009), in the sections that follow it will aid the discussion to have a more concrete idea about what exactly is meant by "anticausativizer." Without going into too much formal detail, I assume, following Levin and Rappaport Hovav (1995) and Rappaport Hovav and Levin (1998), that the lexical semantic representation of causative changeof-state (COS) verbs is as in (53). ${ }^{31}$

(53) The lexical semantics of causative COS verbs [ [ $\mathrm{x}$ do something] CAUSE [ BECOME [ $\mathrm{x}\langle\mathrm{STATE}\rangle]]$

Something like this representation is common in the lexical semantic literature, from Dowty (1979) to Hale and Keyser (1987), Pinker (1989), Parsons (1990), Jackendoff (1990), Piñón (2001), Doron (2003), and others, with formal details differing significantly (from lexicalism to nonlexicalism, event-based to nonevent-based approaches, etc.). All that is important for the discussion that follows is that a transitive/causative verb has some kind of CAUSE component, with the cause argument of a causative verb being one of the arguments of the CAUSE (whether directly, or as a participant in a causing subevent, as in

\footnotetext{
${ }^{29}$ What might need to be rethought is the notion of (in)transitivity in the first place, an issue known, at least since Hopper and Thompson (1980), to be much more complicated than is often assumed.

${ }^{30}$ Even if the natural force construction, upon further investigation, did turn out to be problematic for the analysis of $-d a / w a$ - suggested here, it would certainly be no less problematic for Hale and Salamanca's analysis, which like mine predicts that $-d a / w a-$ verbs are always intransitive. The much more important observations in this paper concern the treatment of -ta/pa-.

${ }^{31} \mathrm{I}$ am simplifying greatly in the interest of perspicuity. For a more formal representation drawing on the lambda calculus, see Koontz-Garboden (2009).
} 
53). There are many ways of formalizing the anticausative operation in a representation like (53), including deletion of the CAUSE and the causer (Grimshaw 1982, Reinhart 2002, Härtl 2003, Reinhart and Siloni 2005, and Kallulli 2006), existential binding of the causing subevent (Levin and Rappaport Hovav 1995 and Marcotte 2005), reflexivization approaches where the single argument of the anticausative verb is treated as both the causer and the causee (Chierchia 2004 and Koontz-Garboden 2009), and little-v approaches where the anticausative is taken to preclude merger with little-v, thereby blocking causativization (Doron 2003). With the exception of the last of these, most analyses agree in taking something like (53) as the input to anticausativization. I assume the same here. Without going into any detail, then, about what exactly anticausativization does formally, the important point for the discussion below is simply that an anticausative operator can operate only on a verb with a lexical semantic representation like (53), the crucial point being that it must be a two-argument verb with a causative component.

6. Lexical semantic asymmetries captured by the analysis. In the preceding sections I have laid out a range of mostly morphosyntactic evidence that suggests that while -ta/pa-do nothing to the lexical semantics of the root to which they suffix, $-d a / w a-$ do. In the sections that follow, I show that this fundamental difference in the nature of the verbal suffixes has consequences for the kinds of change-of-state (COS) events that are encoded by verbs of the different classes. The observation is that the kind of COS events denoted by $-d a / w a$ - verbs is predictable, based on their anticausative function. In contrast, the meaning of verbs in the -ta/pa- classes is unpredictablemany different kinds of meanings are found among verbs with these markers, consistent with the idea that $-t a / p a$ - do nothing to alter the lexical semantics of the root. The evidence comes from two sources-first, the polysemy of roots when used as -ta/pa- as opposed to - $d a / w a$ - verbs and, second, from the kinds of COS events named by verbs of the different classes. Both sources of evidence lend further support to the descriptive claim that while -ta/pado not alter the meaning of roots they suffix to, $-d a / w a-$ do.

6.1. Change-of-state event types in the classes. As mentioned at the outset, intransitive verbs are found in all four morphological classes. Among the observations left undiscussed, however, was that at least in the domain of COS verbs, there is an asymmetry in the kinds of COS events encoded by verbs in the different classes. More specifically, the kinds of COS events found in the $-t a / p a$ - classes are a superset of the kinds found in the $-d a / w a-$ classes. Drawing on the external/internal causation distinction (Smith 1970, Croft 1990, Haspelmath 1993, and Levin and Rappaport Hovav 1995), I show that while there are both internally and externally caused COS verbs 
in the -ta/pa- classes, there are only externally caused COS verbs in the $-d a / w a$ - classes. This asymmetry points to a difference in the lexical semantic nature of the verb class markers. While -ta/pa- allow the various meanings of a COS denoting root to surface without doing anything to it, $-d a / w a-$ do not. Instead, $-d a / w a-$ perform an anticausative operation on roots with transitive/ causative externally caused COS meaning, returning intransitive/inchoative externally caused COS meanings as an output.

I begin by laying out the distinction between internal and external causation. This is followed by discussion and argumentation showing that there are both internally and externally caused COS verbs in -ta/pa-, while there are only externally caused COS verbs in $-d a / w a-$.

6.1.1. Internal versus external causation. Drawing on earlier work by Smith (1970) and Haspelmath (1993), Levin and Rappaport Hovav (1995:chap. 3) propose a broad contrast between two types of eventualities that are lexicalized by verbs, those which are INTERNALLY CAUSED and those which are EXTERNALLY CAUSED, the idea being that events contrast in the degree to which the participant in the caused event is viewed as also being the causer or not. In the words of Levin and Rappaport Hovav, with internally caused verbs (i.e., verbs denoting an event that is internally caused), ". . . some property inherent to the argument of the verb is 'responsible' for bringing about the eventuality" (Levin and Rappaport Hovav 1995:91). This contrasts with the situation for externally caused eventualities, which Levin and Rappaport Hovav describe as eventualities that ". . . by their very nature imply the existence of an 'external cause' with immediate control over bringing about the eventuality ... an agent, an instrument, a natural force, or a circumstance" (Levin and Rappaport Hovav 1995:92). Levin and Rappaport Hovav (1995:90) illustrate this contrast via examination of the verbs shake and shudder, which at first blush appear to be synonymous but turn out to have subtle differences in the direction suggested by the internal/external cause distinction.

(54a) Kim shuddered at the thought of going there.

(54b) The house shook under the force of the earthquake.

(55a) *The thought of going there shuddered Kim.

(55b) The force of the earthquake shook the house.

Levin and Rappaport Hovav's observations (which they attribute to Anthony Kroch) are, first, that while shudder fails to participate in the causative alternation, as shown by the data in (55a), shake does alternate (55b). This fact they attribute to shudder being internally caused and shake being externally caused. As evidence for this, they examine the kinds of things that can shudder and shake, observing that ". . . the set of things that shudder [is] to a large extent a subset of the set of things that shake..." and "things that 
shudder usually can be thought of as having a 'self-controlled' body; they include people, animals, and perhaps by force extension, the earth, engines, machinery, and vehicles. In contrast, leaves, teacups, and furniture, none of which can be said to have a 'self-controlled' body, can only shake" (Levin and Rappaport Hovav 1995:100). This distinction between internally caused and externally caused eventualities, then, is linked to the causative/inchoative alternation in that it is only those eventualities which can be caused by an entity external to the argument of the caused event that can participate in the causative/inchoative alternation. As observed by Levin and Rappaport Hovav, shake names such an event, while shudder does not.

The distinction between internally and externally caused eventualities is murky, and when used as an explanation for participation in the causative/ inchoative alternation, can verge on circularity. ${ }^{32}$ Nevertheless, despite these difficulties, I believe that there is something to the distinction, a conclusion suggested by converging evidence from the corpus-based and psycholinguistic studies of Wright (2001) and McKoon and Macfarland (2000; 2002). ${ }^{33}$ More important in the present context, I believe that Ulwa verb class morphology is sensitive to this distinction. The observation is that while there are both externally caused and internally caused COS events named by -ta/paverbs, only externally caused COS events are named by - da/wa- verbs. Externally caused COS events, when named by a -ta/pa- verb, are transitive, and when named by a $-d a / w a-$ verb are intransitive. Given that $(a)$ externally caused COS events are lexicalized as two participant events and (b) -da/waperform an anticausativizing function on transitive/causative externally caused COS denoting roots, it is expected that the COS events named by intransitive $-d a / w a$ - verbs would be externally caused, since the output of an anticausative operation on almost any well-spelled-out analysis must also be externally caused (Koontz-Garboden 2009). By contrast, since internally caused

\footnotetext{
${ }^{32}$ Despite these concerns, I do believe that it may be possible ultimately to formalize the distinction between internally and externally caused eventualities by drawing on the tools of model-theoretic semantics. The work of Piñón (2001) and Chierchia (2004) is particular relevant here, and I believe could form the basis for a more formal approach and ultimately a better understanding of the internal/external cause distinction. This work, however, lies beyond the scope of this paper.

${ }^{33}$ These studies, though generally supporting the Levin and Rappaport Hovav (1995) contrast between internal and external causation, show that the situation is more complicated, especially with respect to the causative/inchoative alternation. In particular, they show that internally caused change-of-state verbs, contra Levin and Rappaport Hovav (1995), can indeed participate in the causative/inchoative alternation. Nevertheless, this occurs only in a highly restricted set of circumstances, a finding which entails only minor modification to the Levin and Rappaport Hovav (1995) analysis.
} 
COS events are single argument events, as evidenced by their failure to have transitive/causative counterparts, the lexical semantic representation of verbs naming these events does not meet the structural conditions for application of anticausativization, which requires a transitive/causative COS event representation as input to yield an inchoative in the output. As such, it is expected that internally caused COS verbs would be -ta/pa-class verbs, since -ta/pa- have no lexical semantic constraints on their verbalization of roots.

First, I discuss the kinds of change-of-state events found in the two classes, showing that the kinds of events named by verbs of the two classes is consistent with this distinction. I then show that this has consequences for the causative/inchoative alternation.

6.1.2. Different kinds of events. Consistent with Levin and Rappaport Hovav's characterization of the properties of the single argument of internally versus externally caused COS verbs, it seems that the single argument of -ta/pa- COS intransitives does play a role in bringing the event about. This stands in contrast to the properties of the single argument of $-d a / w a-$ verbs. In this section, I consider facts supporting this position.

First, simply consider the kinds of events named by intransitive -ta/pa-vs. $-d a / w a-$ COS verbs. Lists of such verbs in each of the morphological classes are given in (56)-(59).

(56) Intransitive change-of-state verbs in -ta-class (some also have transitive sense)

auhnaka 'become fat'; buhnaka 'become dry (e.g., clothes)'; dutnaka 'spoil/rot'; lalahnaka 'ripen, rot'; lapusnaka 'be/become baggy/sag'; pakapnaka 'stiffen, become rigid'; pânaka 'grow'; paunaka 'turn red'; pînaka 'become blind, dry up (eyes)'; pulunaka 'flower, blossom'; pupuhnaka 'swell'; puruhnaka 'become sunken (cheeks, eyes)'; putnaka 'billow (smoke)'; ripnaka 'cool off'; bangnaka 'to become full'; damnaka 'to sweeten'; sapaknaka 'sour, ferment, spoil'; siunaka 'be fully developed, but not ripe'; tapalhnaka 'spoil, become bitter'; tipitnaka 'congeal, coagulate, harden'; tubaknaka 'become thick/overgrown (e.g., trees)'; wirunaka 'shrivel, dry out (green, unripe fruit)'; nanaknaka 'curdle'; pulingnaka 'blister'

(57) Intransitive change-of-state verbs in -pa-class (some also have transitive sense)

ingnaka 'to become light/light up'; baknaka 'to rot, perish, get/be drunk'; wanihnaka 'to become pregnant again'; babarnaka 'become thin'; amatnaka 'swell (river)'; batanaka 'become a man'; rukuhnaka 'become bumpy/break out in hives'; tutuhnaka 'become bumpy/break out in hives'; lusuhnaka 'become flaky'; lamnaka 'calm (e.g., body 
of water)'; lamatnaka 'swell (water)'; dalaunaka 'become gooey'; rainaka 'form slick on water'; aisaunaka 'disappear'; buhutnaka 'become cloudy'; barahnaka 'burn partially/incompletely'; minisihnaka 'become dirty'; tînaka 'become rusty/get out of practice'; disnaka 'become silent, quiet down'; dasinaka 'become strong'; wasaknaka 'become tangled, become embroiled in a fight'; lilisnaka 'become tattered, ragged'; witnaka 'become used up'; tatasnaka 'get dirty'; ahaunaka 'loosen, become loose'; raunaka 'ripen, but not fully, just before softening'; bisinaka 'shrink by losing some'

(58) Intransitive change-of-state verbs in - $d a$ - class abaldanaka 'go bad'; abukdanaka 'capsize'; alhdanaka 'burst'; babardanaka 'become thin'; baradanaka 'become dark'; barasdanaka 'become black'; birhdanaka 'tear, rip, shred'; birikdanaka 'cover oneself '; bukdanaka 'chip, crack'; dakdanaka 'snap, sever completely'; didiudanaka 'stretch/become stretched'; dulukdanaka 'get soaked'; kalhdanaka 'crush, break'; karadanaka 'melt/dissolve'; karhdanaka 'become stuck'; kingdanaka 'become clogged'; kubitdanaka 'bend at joint'; kumdanaka 'catch fire'; kurudanaka 'become unstitched'; lamatdanaka 'dent, become dented, collapse'; lisdanaka 'split/cleave'; luhusdanaka 'foam/froth'; muhdanaka 'wake up'; patdanaka 'burst, rupture, pop'; pildanaka 'chip/flake'; pitukdanaka 'turn inside out'; puidanaka 'cool/become lukewarm'; puradanaka 'become wet'; pusingdanaka 'swell'; raidanaka 'become slicked with oily sheen on surface'; raudanaka 'stand up/get up (from bed)'; rîdanaka 'open (sail)'; rubukdanaka 'become shorter'; sangdanaka 'turn green'; sayakdanaka 'become dislocated'; siritdanaka 'become wrinkled'; subitdanaka 'come loose'; suihdanaka 'break; snap off'; takdanaka 'chip, flake off, peel'; tarakdanaka 'tangle'; turudanaka 'flake (skin)'; ulangdanaka 'be or become mucky'; uluhdanaka 'loosen'; urundanaka 'curl up in fetal position'; warindanaka 'become crooked'; wiridanaka 'become twisted'; wiringdanaka 'inflate, become inflated'; yamdanaka 'become'; yûhdanaka 'lengthen/ become long'; yurahdanaka 'open (mouth)'

(59) Intransitive change-of-state verbs in -wa- class alawanaka 'to grow'; ituwanaka 'grow in size'; mahwanaka 'fill (stomach)'; nakawanaka 'wound self (accidentally)'; purawanaka 'become wet (on purpose)'; sikwanaka 'become larger'; singwanaka 'heal/awaken'; bahwanaka 'break (become non-functional)'; dakwanaka 'rip, tear, break'; dâwanaka 'burn'; diswanaka 'go out, stall'; îwanaka 'die, be sick'; lahwanaka 'boil, cook'; sahwanaka 'split, crack open, burst' 
Intransitive change-of-state events in the -ta/pa- classes, on a very general level, are events which in some sense are brought about by their single argument. These are events such as spoiling, rotting, blossoming, fermenting, swelling (water), calming (water), ripening (fruit), becoming dry (clothes), becoming nearly ripe (fruit), congealing (fat), curdling (milk). In contrast, those in the -da/wa- class involve some sort of external cause, events such as breaking, tearing, cracking, cooking, loosening, getting soaked, etc. ${ }^{34}$

More convincing than simply looking at these glosses, however, is evidence coming from "doublets." It turns out that there are certain roots that have change-of-state intransitives in both the -ta/pa- and the - $d a / w a$ - classes. Whenever this happens, the COS verb in the -ta/pa-class has more of an internally caused type meaning, contrasting with the externally caused type meaning of the $-d a / w a-$ doublet. The first example comes from the root sah-, which forms a verb not only in the -ta-class but in the - $w a$ - class as well. This is illustrated in (60), with an example in which the root surfaces as an intransitive - $t a$ - verb in $(60 a)$ and as an intransitive - $w a$ - verb in $(60 b)$.

(60a) Kat-ki-taramah suma-ka $\begin{aligned} & \text { aslah } \\ & \text { chicken- }\langle 1 \mathrm{SING}\rangle\end{aligned}$ egg-3sing
sah-t-ida.

'The one egg that my chicken had hatched'. (I.e., a chick emerged from it; notes, 988)

\footnotetext{
${ }^{34} \mathrm{An}$ anonymous reviewer was skeptical about the internal/external causation distinction, observing that both a -wa-class verb alawanaka and a -ta-class verb pânaka are glossed as 'grow'. I believe that rather than cause for skepticism, the existence of this pair of verbs offers promise for fruitful research of the shake/shudder kind (discussed above) that helped Levin and Rappaport Hovav (1995) elucidate the internal/external cause distinction in the first place. Unfortunately, I have not yet collected enough data on these two particular verbs to be able to understand their lexical semantics to this fine a degree. There are differences between the two verbs, to be sure. In the relatively small number of examples I presently have, I find that the kinds of subjects that alawanaka takes are clearly different from the kinds of subjects pânaka takes. While there are examples of alawanaka being used to discuss the growth of a child (dict), a store (notes, 965), cows (notes, 1056), and a tree (dict), pânaka is thus far found mostly with plants, particularly trees (dict and notes), but also grass (dict; notes, 970), cassava (dict), and cane (dict). In some more colorful examples, however, it is found also to describe growth of the tip of a chicken's tongue (dict), some particular body part in the gut (dict), and the sprouting of teeth from a crocodile's mouth (dict). Thus, while I agree with the reviewer that something should ultimately be said about this pair of verbs, it is not yet obvious to me that the pair is a counterexample to the empirical generalization that internally caused change-of-state verbs are in -ta/pa-, with intransitive externally caused change-of-state verbs in -da/wa-. There is quite clearly some subtle distinction in the meanings of the two verbs that further work should try to elucidate, and which will, I believe, shed more light on the nature of the distinction between internal and external causation.
} 


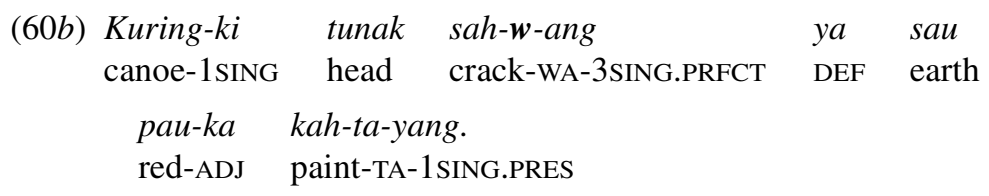

'I am caulking the crack in the prow of my canoe'. (Green 1999:242)

The contexts of use of the -ta-verb in $(60 a)$ with a chick hatching and the $-w a$ - verb in $(60 b)$ with a crack in a canoe are not accidental. As it turns out, different senses are available to the root depending on the morphological class in which it is used. This is illustrated in (61).
(61) Kat-ki-taramah suma-ka aslah watah dai ya chicken-〈1SING $\rangle$ egg-3SING one have PAST DEF sah-w-ida. split-WA-3SING.PAST

(a) 'The one egg that my chicken had cracked'. (I.e., something happened to it, and it cracked prior to the time it was supposed to, thereby preventing a chick from hatching; notes, 988)

(b) *'The one egg that my chicken had hatched'. (I.e., a chick emerged from it; notes, 988)

In (61), there is crucially an inference that a chick did not emerge from the egg alive; instead, the egg got cracked somehow, PREVENTING it from hatching, i.e., killing the chick. In terms of the internal/external cause distinction under discussion, for the 'hatch' sense of sah-, which surfaces in the -ta-class, it seems fair to say that the single argument of the verb itself causes the eventuality to come about; there is no real sense in which there is a cause external to a chick that is responsible for its hatching. In contrast to the single argument of its -wa-counterpart, however, as the data in (61) clearly show, there is by necessity a cause external to the chick responsible for causing the cracking of the egg, and ultimately for the death of the chick. This root, then, when used as an intransitive verb in the - $t a$ - class has an internally caused sense, while it has an externally caused sense when used as a -wa-class intransitive.

Not to be overlooked in this discussion is the fact that there are transitive uses of the root sah- as well, as illustrated by the data in (62).

(62) Yang pan as $\begin{array}{lll}\text { ahai-t-ikda } & \text { ya yan } \\ \text { 1SING log INDEF } & \text { bring-TA-1SING.PAST the tomorrow } \\ \text { sah-t-uting. } & & \end{array}$ split-TA-1SING.FUT

'Tomorrow I am going to split this log that I brought'. (dict) 
(62) illustrates a canonical externally caused verbal sense-there is a cause (an agent) external to the log, which causes it to become cracked. As there are no transitives in $-w a$ - or $-d a$-, this transitive use is necessarily in the $-t a$ or the - $p a$ - class, in this case the former. Thus, for the root $s a h$ - in the $-t a$ class, there are both externally caused (transitive) and internally caused (intransitive) senses. This contrasts with the situation for the -wa-class, for which there is only an externally caused sense, corresponding to the transitive, externally caused sense of the -ta-verb highlighted in (62). ${ }^{35}$

Another doublet example supporting the claim that $-d a / w a$-intransitive change-of-state verbs are externally caused while - $t a / p a$ - intransitive changeof-state verbs are internally caused parallels Levin and Rappaport Hovav's (1995) shake/shudder example. The root isi- broadly means something like 'shake'. When used as a - $d a$ - class verb, it has a meaning consistent with external causation. When used in the - $p a$ - class, however, it means something like 'shake', though it is used only in the case of the earth shaking, as in an earthquake, something which does not obviously have a cause external to the earth itself. Examples illustrating this contrast are given in (63).

$\begin{array}{ccccc}\text { (63a) } \begin{array}{c}\text { Balauh } \\ \text { table }\end{array} \text { DEF } & \begin{array}{l}\text { Andrew } \\ \text { Andrew }\end{array} & \begin{array}{l}\text { yam-ka } \\ \text { good-ADJ }\end{array} & \begin{array}{l}\text { yam-ta-sa } \\ \text { make-TA-3SING.NEG }\end{array} \\ \text { dai } & \text { bahangh } & \text { yam-ka } & \text { sak-wa-sa. } \\ \text { PAST.AUX } & \text { because } & \text { good-ADJ } & \text { stand-WA-3SING.NEG }\end{array}$

Isi-d-ai.

shake-DA-3SING.PRES

'The table does not stand well, because Andrew did not make it well.

It shakes'. (notes, 1020)

(63b) Asang isi-p-ai.

earth/village shake-PA-3SING.PRES

'The earth/village shakes'. (notes, 1046)

\footnotetext{
${ }^{35}$ An anonymous reviewer remarks, "if -ta/pa- does not alter the root, how come, then, the same root can appear as intransitive and as transitive with the same verbalizer -ta/pa-? The author's proposal predicts that the -ta/pa- marker attached to the same root will only be able to surface as one single type, as it doesn't affect it." In fact, my analysis makes the opposite prediction-because -ta/pa- do nothing to the meaning of the root, any sense of the root can surface under -ta/pa- suffixation. Stated another way, unlike - $d a / w a-$, which yield a particular lexical semantic output (an anticausative) from a particular (transitive causative) input, this is not so for -ta/pa-, which are completely semantically transparent. They allow any meaning to surface, their sole function being a structural one, to derive a verbal stem (whatever its meaning) from a root. There is nothing in this to preclude a -ta/pa-verb having multiple senses; on the contrary, if -ta/pa- do nothing to the meaning of the root, it would be surprising if -ta/pa-verbs only had a single sense, as is the case for $-d a / w a$ - verbs.
} 
There is not any obvious external event that causes an earthquake, though a table might shake as a result, e.g., of just walking around in a rickety house. This difference between the $-p a$ - and $-d a$ - class variants surfaced quite clearly in the naturally occurring example in (64).

$\begin{array}{llll}\text { Asang } & \text { isi-p-ai } & \text { kau } & \text { asang } \\ \text { earth/village } & \text { shake-PA-3SING.PRES } & \text { when } & \text { earth/village } \\ & \begin{array}{l}\text { isi-d-ai. } \\ \text { shake-DA-3SING.PRES }\end{array}\end{array}$

'When the earth shakes (quakes), the village shakes'. (notes, 1020)

Note that the verb used to describe the shaking of the earth is in the -paclass, while the one used to describe what happens to the village when the earth shakes is in the - $d a$ - class. In (64), the earthquake is the external cause of the shaking of the village, the former being an internally caused event, the latter externally caused.

As in the example discussed above with the -ta-themed sahnaka, which has uses both as an externally caused transitive and as an internally caused intransitive, the same is true for - pa-themed isinaka, as shown by the internally caused intransitive uses in (63) and (64) alongside the externally caused transitive use in (65).

Andrew w-î balauh ya wâ-t-i
Andrew come-ss table the grab-TA-SS
isi-p-ida.
shake-PA-3SING.PAST

'Andrew came, grabbed, and shook the table'. (notes, 1020)

As with the sah-doublet, what is found for isi-is that the root has a transitive externally caused sense in -ta/pa-, an intransitive internally caused sense in $-t a / p a-$, as well as an intransitive externally caused sense in - $d a / w a-$. Stated another way, the root has both internally and (transitive/causative) externally caused senses. The structural description for the application of anticausativization with - $d a / w a$ - is met only by the externally caused sense of the root, thereby explaining why the $-d a$ - class isidanaka has an externally caused sense.

A final example illustrating the same phenomenon comes from doublets with the root birh-, which as a - $p a$ - class intransitive verb denotes a stinking event, while as a - $d a$ - class intransitive verb it denotes a tearing event, as illustrated by the sentences in (66). 


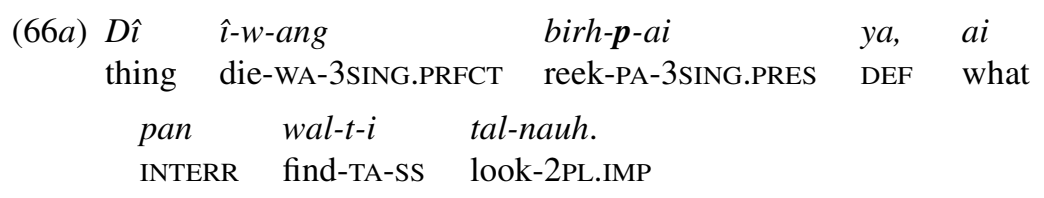

'Go find out what the dead thing that reeks is'. (notes, 984)

$\begin{array}{llll}\text { (66b) Asna } & \text { ya } & \text { andih } & \text { birh-d-ida. } \\ \text { cloth/shirt } & \text { DEF } & \text { already } & \text { tear-DA-3SING.PAST }\end{array}$

'The cloth/shirt is already torn'. (notes, 985)

While something dead naturally progresses to a state of stench on its own, we do not typically conceive of cloth/shirts as progressing on their own to a state of "tearedness." When they are torn, we typically envision this happening as a result of some external cause. Now it is possible, of course, to conceive of clothing becoming torn and ragged simply as a result of becoming old, part of the natural progression of any entity. This kind of eventuality in Ulwa, however, is described with a verb different from the - $d a$ - class birhdanaka in (66). Instead, such an eventuality is described using the -paclass verb lilisnaka, as shown in (67), a fact further supporting the claim that internally caused COS events are in the $-t a / p a$ - classes, not the $-d a / w a$ - ones.

$$
\begin{array}{lllll}
\text { Kahlu } & \text { balna } & \text { bu } & y a & \text { lilis-p-ida. } \\
\text { shirt } & \text { PL } & \text { two } & \text { the } & \text { shred-PA-3SING.PAST }
\end{array}
$$

'The two shirts have turned to rags'. (notes, 1058)

Finally, as with the other examples discussed above, the -ta/pa- variant has not only an intransitive internally caused sense but also a transitive externally caused sense, which itself corresponds to the intransitive externally caused sense that shows up in $-d a / w a-$. A transitive externally caused use of the -pa-themed verb birhnaka is given in (68).

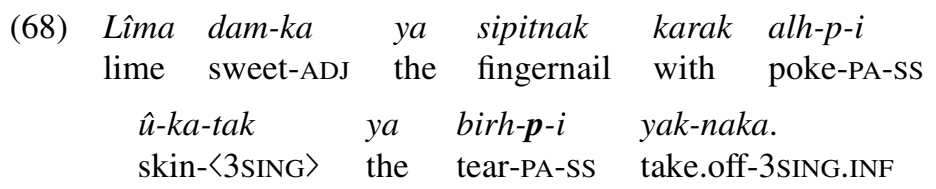

'We have to poke the skin of the sweet lime with our fingernail in order to rip and take off its skin'. (dict)

The overall conclusion, then, is that $-d a / w a$ - intransitive change-of-state verbs are externally caused, derived from the externally caused transitive causative sense of the root via anticausativization, while -ta/pa-intransitive 
change-of-state verbs can be internally caused. As I show in 6.1.3, data from the causative/inchoative alternation converge on this same conclusion.

6.1.3. The causative/inchoative alternation. The clearest morphosyntactic diagnostic suggested by Levin and Rappaport Hovav (1995) for determining whether a predicate is internally or externally caused is participation in the causative/inchoative alternation, illustrated in (69), in which a verb root has both an incarnation as a causative verb (69a) and as an inchoative verb $(69 b)$.

\author{
(69a) Arak-ki-bus bah-t-ikda. \\ gun-〈1sING $\rangle$ break-TA-1SING.PAST \\ 'I broke my gun'. (dict)

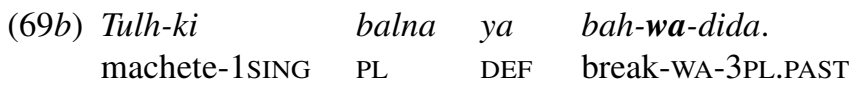

'My machetes broke'. (notes, 1059)

The prediction of Levin and Rappaport Hovav's analysis (1995:chap. 3) is, as discussed above, that only externally caused verbs alternate. In Ulwa, this diagnostic reveals a distinction between intransitive change-of-state verbs in the -ta/pa- classes and those in the - $d a / w a$ - classes-while intransitive verbs in the former class, as discussed above, sometimes alternate, those in the latter class almost always do. ${ }^{36}$ This latter point is illustrated by the lists in (70)-(72), which give COS verbs in the -da/wa- classes and whether or not they have a transitive counterpart in -ta/pa-.

(70) Change-of-state verbs in - $d a$ - class

$\begin{array}{lll}\text { Verb } & \text { Gloss } & \text { Class of Transitive Alternate } \\ \text { abaldanaka } & \text { go bad } & -t a- \\ \text { abukdanaka } & \text { capsize } & -p a- \\ \text { alhdanaka } & \text { burst } & -p a- \\ \text { babardanaka } & \text { become thin } & \begin{array}{c}\text { No transitive alternate } \\ \end{array} \\ & & \text { (intransitive doublet in }-p a-\text { ) } \\ \text { baradanaka } & \text { become dark } & -p a- \\ \text { barasdanaka } & \text { become black } & -p a- \\ \text { birhdanaka } & \text { tear, rip, shred } & -p a- \\ \text { birikdanaka } & \text { cover oneself } & -p a-\end{array}$

${ }^{36}$ As shown in (70) and (71), there are seven counterexamples (out of 68 total pairs) to the prediction that $-d a / w a-C O S$ verbs always have a transitive/causative -ta/pa- counterpart. I agree with an anonymous reviewer who calls these counterexamples a "loose end" in the analysis. At the same time, I am not sure whether one should be surprised by a small number of counterexamples when dealing with the domain of lexical semantics; but this is certainly a matter that could be debated. 


\begin{tabular}{|c|c|c|}
\hline bukdanaka & chip, crack & $-p a-$ \\
\hline dakdanaka & $\begin{array}{l}\text { snap, sever } \\
\text { completely }\end{array}$ & $-t a-$ \\
\hline didiudanaka & $\begin{array}{l}\text { stretch/become } \\
\text { stretched }\end{array}$ & $-p a-$ \\
\hline dulukdanaka & get soaked & $-p a-$ \\
\hline kalhdanaka & crush, break & -ta/pa-(unclear which) \\
\hline karadanaka & melt/dissolve & $-p a-$ \\
\hline karhdanaka & become stuck & $-p a-$ \\
\hline kingdanaka & become clogged & $-p a-$ \\
\hline kubitdanaka & bend at joint & $-p a-$ \\
\hline kumdanaka & catch fire & $-p a-$ \\
\hline kurudanaka & $\begin{array}{l}\text { become } \\
\text { unstitched }\end{array}$ & $-p a-$ \\
\hline lamatdanaka & $\begin{array}{l}\text { dent, become } \\
\text { dented, collapse }\end{array}$ & $\begin{array}{l}\text { No transitive alternate } \\
\quad(\text { intransitive doublet in }-p a-\text { ) }\end{array}$ \\
\hline lisdanaka & split/cleave & $-p a-$ \\
\hline luhusdanaka & foam/froth & $-p a-$ \\
\hline muhdanaka & wake up & $-t a-$ \\
\hline patdanaka & burst, rupture, pop & $-t a-$ \\
\hline pildanaka & chip/flake & $-t a-$ \\
\hline pitukdanaka & turn inside out & $-t a-$ \\
\hline puidanaka & $\begin{array}{c}\text { cool/become } \\
\text { lukewarm }\end{array}$ & $-t a-$ \\
\hline puradanaka & become wet & $-t a-$ \\
\hline pusingdanaka & swell & $-t a-$ \\
\hline raidanaka & $\begin{array}{l}\text { become slicked with } \\
\text { oily sheen on surfac }\end{array}$ & $\begin{array}{l}-p a- \\
c e\end{array}$ \\
\hline raudanaka & $\begin{array}{l}\text { stand up/get up } \\
\text { (from bed) }\end{array}$ & $-t a-$ \\
\hline rîdanaka & open (sail) & $-p a-$ \\
\hline rubukdanaka & become shorter & $-p a-$ \\
\hline sangdanaka & turn green & $-p a-$ \\
\hline sayakdanaka & become dislocated & $-p a-$ \\
\hline siritdanaka & become wrinkled & No transitive alternate \\
\hline subitdanaka & come loose & $\begin{array}{l}\text { No transitive alternate } \\
\quad(\text { intransitive doublet in }-p a-\text { ) }\end{array}$ \\
\hline suihdanaka & break; snap off & $-p a-$ \\
\hline takdanaka & chip, flake off, peel & $-p a-$ \\
\hline tarakdanaka & tangle & $-p a-$ \\
\hline turudanaka & flake (skin) & $-p a-$ \\
\hline ulangdanaka & be or become mucky & No transitive alternate \\
\hline
\end{tabular}




\begin{tabular}{|c|c|c|}
\hline uluhdanaka & loosen & $-p a-$ \\
\hline urundanaka & $\begin{array}{l}\text { curl up in fetal } \\
\text { position }\end{array}$ & No transitive alternate \\
\hline warindanaka & become crooked & $-p a-$ \\
\hline wiridanaka & become twisted & $-p a-$ \\
\hline wiringdanaka & $\begin{array}{l}\text { inflate, become } \\
\text { inflated }\end{array}$ & $-p a-$ \\
\hline yamdanaka & become & $-t a-$ \\
\hline yûhdanaka & $\begin{array}{l}\text { lengthen/become } \\
\text { long }\end{array}$ & $-p a-$ \\
\hline yurahdanaka & open (mouth) & $-p a-$ \\
\hline
\end{tabular}

(71) Change-of-state verbs in -wa- class

\section{Verb}

alawanaka

ituwanaka

mahwanaka

nakawanaka

purawanaka

sikwanaka

singwanaka

bahwanaka

dakwanaka

dâwanaka

diswanaka

iwanaka

lahwanaka

sahwanaka

\section{Gloss}

to grow grow in size fill (stomach) wound self (accidentally) become wet (on purpose) become larger heal/awaken break (become nonfunctional) rip, tear, break burn go out, stall die, be sick boil, cook split, crack open, burst
Class of Transitive Alternate $-t a-$ $-p a-$ -ta-

No transitive alternate

$-t a-$

$-p a-$

$-p a-$

$-t a-$

$-t a-$

$-t a-$

$-t a-$

$-t a-$

$-t a-$

$-t a-$

(72) Change-of-state verbs relating to body posture (all -wa-with -patransitives)

$\begin{array}{lll}\text { Verb } & \text { Gloss } & \text { Class of Transitive Alternate } \\ \text { sakwanaka } & \text { 'to stand up' } & -p a- \\ \text { lauwanaka } & \text { 'to sit down' } & -p a- \\ \text { kutwanaka } & \text { 'to lie down' } & -p a- \\ \text { witwanaka } & \text { 'to hang' } & -p a- \\ \text { etc. } & & \end{array}$


The lists above were made by extracting all of the verbs from each of the classes from the Ulwa dictionary, which included 616 verbs at last count, before some additions, including some which are relevant for the numbers given in n. 37, based on recent fieldwork (e.g., the transitive kalhnaka 'crush', kumnaka 'set fire', and siknaka 'to enlarge'). ${ }^{37}$ I then manually extracted those $-d a / w a$ - verbs that denote changes of state. In total, there are $50-d a-$ COS verbs, which are listed in (70), and 14 in -wa-, which are listed in (71). This does not include the COS verbs relating to body posture in (72). Although these clearly support the claim here, I have separated them simply because there are so many of them and because there is a clearly productive pattern, such that any posture predicate (e.g., lau 'sit') has a - $w a$ - inchoative and a - $p a$ - causative derived from it. As the lists reveal, there are few (7 out of the 64 nonbody posture COS verbs) intransitive COS verbs in $-d a / w a$ - that do not have transitive/causative counterparts in $-t a / p a-$. This kind of consistent causative/inchoative alternation is a hallmark of external causation according to Levin and Rappaport Hovav (1995) and those their work is based on.

By contrast, there is a relatively large class of intransitive -ta/pa- verbs, already given in (19) and (20) above, (a) many of which do not alternate and (b) even if they do alternate, do not do so across morphological verb classes,

\footnotetext{
${ }^{37}$ A rough tabulation of the numbers of intransitive, transitive, and ditransitive verbs in each of the major classes, excluding the smaller and less regular classes (taken from Green 2004) yields the numbers in $(i)$.
}

(i) Intransitive, transitive, and ditransitive verbs in the major classes

$\begin{array}{lrrrr} & -d a- & -w a- & -t a- & -p a- \\ \text { Intransitive } & 131 & 34 & 33 & 71 \\ \text { Transitive } & 8 & 2 & 79 & 199 \\ \text { Ditransitive } & 0 & 0 & 3 & 2\end{array}$

The general trends (-da/wa- verbs are mostly intransitive, while both intransitives and transitives are well represented in -ta/pa-) are clear from this.

Worth briefly commenting on is, as shown, that there are listed a small number of transitive $-d a / w a$ - verbs. These should be examined; some may be misclassified (e.g., classified as transitive on the basis of natural force uses like those discussed in 5). Others, e.g., (ii), look, at least on the basis of current knowledge, like genuine transitive uses and are thus unexpected from both the current and Hale and colleagues' analyses.

\begin{tabular}{|c|c|c|c|c|c|c|c|c|}
\hline $\begin{array}{l}\text { (ii) } D \hat{\imath} \\
\text { animal }\end{array}$ & $\begin{array}{l}\text { ittingka } \\
\text { killer }\end{array}$ & $\begin{array}{l}a l-k a \\
\text { man-3sING }\end{array}$ & $\begin{array}{l}\text { balna } \\
\text { PL }\end{array}$ & $\begin{array}{l}y a \\
\mathrm{DEF}\end{array}$ & $\begin{array}{l}\text { damaska } \\
\text { bush }\end{array}$ & $\begin{array}{l}\text { kau } \\
\text { to }\end{array}$ & $\begin{array}{l}\text { yaw-i } \\
\text { go-sS }\end{array}$ & $\begin{array}{l}d \hat{\imath} \\
\text { animal }\end{array}$ \\
\hline $\begin{array}{l}\text { balna } \\
\text { PL }\end{array}$ & spy-D & $\begin{array}{l}\text { dai, } \\
\text { PL.PRES }\end{array}$ & $\begin{array}{l}-i \\
11-\mathrm{TA}-\mathrm{SS}\end{array}$ & eat- & $\begin{array}{l}k a \\
\text { ING.INF }\end{array}$ & $\begin{array}{l}\text { val-da } \\
\text { Nant-3 }\end{array}$ & L.PRES & $\begin{array}{l}\text { kau. } \\
\text { when }\end{array}$ \\
\hline
\end{tabular}

'When hunters want to kill and eat something, they go to the bush and lie in wait for animals'. (dict)

Obviously these examples should be examined in more detail. I believe it is worth nothing, though, as evidenced by the data in $(i)$, that they are rare. 
having both transitive and intransitive alternates in the same morphological verb class. The first of these observed possibilities, nonalternation, was already illustrated by the data in (12)-(14) and is further illustrated in (73)-(77).

(73a) Baka-ki al ya andih bata-p-ai

child-1SING male DEF already man-PA-3SING.PRES

bahangh tukka tî-ka balna yam-t-i

because work heavy-ADJ PL do-TA-SS

$y \hat{a}-t-a i$.

1SING.NON-NOM-give-TA-3SING.PRES

'Since my son is fast becoming a man he does the heavy work for me'. (dict)

(73b) *Yang (raupi) baka-ki al ya bata-p-uting.

1 SING (RAUPI) child-1SING male DEF man-PA-3sing.FUT

'I will raise my son into a man'. (notes, 474)

(74a) Was isau lau-t-ida bahangh wassik ya

water much fall-TA-3SING.PAST because river DEF

amat-p-ida.

swell-PA-3SING.PAST

'Because it rained a lot, the river swelled'. (notes, 989)

(74b) *Alah was baka ya amat-p-ida.

God water small DEF swell-PA-3sING.PAST

'God swelled the stream'. (notes, 459)

(75a) Sûlu as watah yang katka babar-p-ida dog INDEF have 1SING but thin-PA-3SING.PAST

bahangh wal-ta-sing.

because want-TA-1SING.NEG

'I have a dog that has become thin, so I no longer want him/her'. (notes, 449)

(75b) *Yang raupi sû-ki-lu babar-p-ikda, kanas

1 SING RAUPI dog-〈1SING thin-PA-1SING.PAST more

auh-ka dai bahangh.

fat-ADJ PAST.COP because

'I thinned my dog up because he was so fat'. (notes, 968) 
(76a) $\hat{U}$ dipih-ka, was lau-t-ai kau sirih-ka house lawn-3SING water fall-TA-3SING.PRES when fast-ADJ tubak-t-ai.

thick-TA-3SING.PRES

'When it rains, the lawn quickly becomes overgrown'. (notes, 970)

(76b) * $\hat{U}-k i \quad$ dipih-ka tubak-t-uting.

house-1SING lawn-3SING thick-TA-1SING.FUT

'I am going to overgrow my lawn'. (notes, 970)

(77a) Turuh auhka balna tipit-t-ai. cow fat PL congeal-TA-3SING

'The fat of the cow congeals'. (notes, 969)

(77b) *Turuh auhka ya tipit-t-uting. cow fat DEF congeal-TA-3SING.FUT

'I'm going to congeal the fat of the cow'. (notes, 969)

In contrast, there are other intransitive change-of-state verbs in the -ta/paclasses that do participate in the causative/inchoative alternation, as shown in (78) and (79).

(78a) Bâwas, tining karak yak wat-ya kau, mâ diarrhea vomit with 1PL.INCL catch-3SING when day bû datak mikdini ya andih puruh-t-ai. two after eye.1PL.INCL DEF already deep-TA-3SING.PRES

'After two days of diarrhea and vomiting our eyes are already sunken'. (dict)

(78b) Yang nuh-ki ya kanas puruh-ta-yang,

1SING mortar-1SING DEF more deep-TA-1SING.PRES

$\begin{array}{llllll}\text { pihmak } & \text { ya } & \text { kanas } & \text { isau } & \text { wat-rang } & \text { yulka. } \\ \text { rice } & \text { DEF } & \text { more } & \text { much } & \text { fit-3SING.IRR } & \text { so.that }\end{array}$

'I'm deepening my mortar so it will hold more rice'. (dict)

(79a) Kasnaka dî-ka mah-ka kas-ring laih food thing-3SING much-ADJ eat-3sing.IRR if

auh-ta-ring.

fat-TA-1 SING.IRR

'If I eat a lot I will become fat'. (dict) 


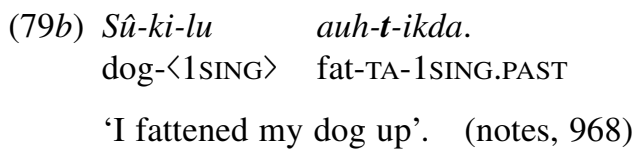

In contrast to the situation with the alternating verbs in (70)-(72), where the intransitive and transitive variants fall into different morphological classes, with the alternations in (78) and (79), there is no change in morphological class associated with the transitivity alternation. Instead, both intransitive and transitive are in the $-t a / p a$ - classes. Whether the inchoative and causative in examples like (78) and (79) are best classified as both externally caused, or as separate senses, with the intransitive variant internally caused and the transitive externally caused, is a matter that merits additional investigation. The important point here is not so much whether all -ta/pa-intransitive COS verbs are internally caused as it is whether at least some are, and whether all $-d a / w a-$ COS verbs are externally caused. The analysis of -ta/pa- as doing nothing to alter root meaning allows for any kind of meaning with -ta/paverbs, whether internally or externally caused. We know for certain that there are externally caused senses among the - $t a / p a$ - verbs since all causatives are in this class, and that there are internally caused senses in this class, on the basis of the existence of nonalternating intransitive COS verbs in this class as well as the lexical semantic evidence discussed above. The analysis of $-d a / w a$ - as anticausativizers with change-of-state verbs, however, predicts that inchoative $-d a / w a$ - verbs can only be externally caused. The evidence from the causative alternation discussed in this section supports this prediction.

6.2. Polysemy in -ta/pa- versus -da/wa-. As evidenced by the lists in (70)-(72), it is often the case in Ulwa that a given root can form a verb in both the -ta/pa- and the $-d a / w a$ - classes. As already discussed, this is how the causative/inchoative alternation is often marked, with the root having transitive/causative meaning when suffixed by -ta/pa-, as in $(80 a)$, and inchoative meaning when suffixed by $-d a / w a-$, as in $(80 b)$.

(80a) Arak-ki-bus bah-t-ikda.

gun-〈1SING〉 break-TA-1SING.PAST

'I broke my gun'. (dict)

$\begin{array}{llll}\text { (80b) } I l-w \text {-ing } & k a u & \text { atak } & y a \\ \text { ascend-WA-1SING.PRFCT } & \text { when } & \text { stairway } & \text { DEF }\end{array}$

bah-w-ida.

break-WA-3SING.PAST

'When I climbed up the stairway, it broke'. (dict) 
In pairs like those in (80), the root has the same basic kind of sense, whether suffixed by -ta/pa- or $-d a / w a-$; in both cases, a breaking event is described, one causative, one inchoative. It is often the case, however, that the -ta/paclass verb has additional senses unavailable to the $-d a / w a$ - verb. Data already discussed in the context of the internal/external causation distinction above along with data introduced in this section illustrate this point.

The generalization that emerged regarding internal and externally caused change-of-state verbs in $\mathbf{6 . 1}$ above was that for intransitive change-of-state verbs, those that are internally caused are in the $-t a / p a$-classes, while those that are externally caused are in the $-d a / w a$ - classes. Additionally, however, a point made less forcefully was that the $-d a / w a$ - externally caused intransitive verbs (with few exceptions listed above) have a transitive/causative counterpart in -ta/pa-, a fact predicted by the treatment of $-d a / w a-$ as anticausativizers. Among the data from above that best illustrate this point are those illustrating the various senses of the root birh- in (66) and (68), reintroduced below. The data in (81) illustrate the 'tear' sense of the root birh-. As expected, given the understanding of the causative/inchoative alternation discussed above, the transitive/causative sense surfaces as a -ta/pa-class verb, as shown in $(81 a)$, the intransitive/inchoative sense as a $-d a / w a$ - class verb, as shown in $(81 b)$.

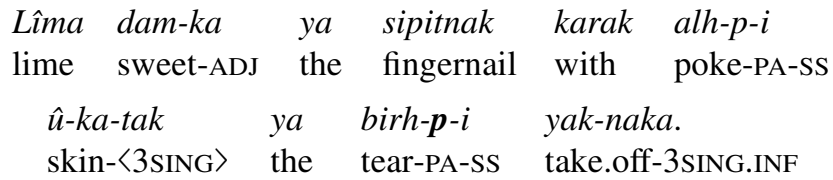

'We have to poke the skin of the sweet lime with our fingernail in order to rip and take off its skin'. (dict)

(81b) Asna ya andih birh-d-ida. cloth/shirt DEF already tear-DA-3SING.PAST

'The cloth/shirt is already torn'. (notes, 985)

In addition to the 'tear' sense, however, as already illustrated above, birhhas another, quite different sense of 'reek'. Crucially, as illustrated in (82), when birh- has this sense, it surfaces as a -ta/pa-class verb.

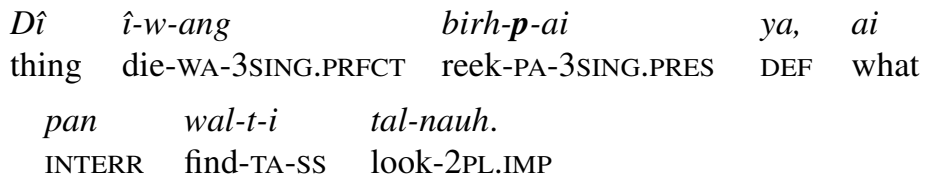

'Go find out what the dead thing that reeks is'. (notes, 984) 


\section{birhnaka (-ta- class verb)}

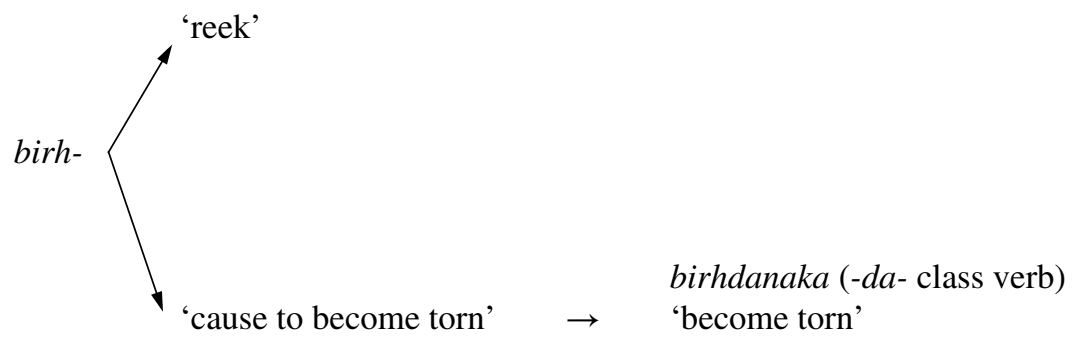

FIG. 3.-The senses associated with the root birh-.

The root birh-, then, has two quite different senses: 'tear', for which there are both - $t a$ - and - $d a$ - class verbal stems, and 'reek', for which there is a -ta-class verb but no $-d a / w a$ - class counterpart. The situation illustrated by this set of data, then, is one where the - $t a$ - class verbal stem has a superset of the senses associated with the $-d a$ - class stem. This state of affairs is illustrated graphically in figure 3. As it shows, the root birh- has two separate senses lexically associated with it, 'reek' and 'cause to become torn'. Only the latter of these senses meets the structural description of the anticausative operation marked by $-d a / w a-$, and it is for this reason that only the 'tear' sense surfaces as a $-d a / w a$ - class verb. The -ta/pa- suffixes, by contrast, simply verbalize the root, allowing any and all of the lexically listed senses of the root to surface. In this way, the greater degree of polysemy observed for the - $p a$-class birhnaka when compared to the - $d a$ - class birhdanaka is expected. The same kind of behavior repeats itself in case after case, as illustrated by the internal/external cause examples discussed above and by the additional examples highlighted below.

The data in (83) and (84) provide another, parallel example. The root $d u t$ - has two separate senses: 'remove' and 'rot'. ${ }^{38}$ While the 'remove' sense surfaces as both a - $t a$ - class causative change-of-state verb (83a) and as a - $d a$ - class inchoative $(83 b)$, the 'rot' sense can surface only as a -ta-class verb, as shown in $(84 a)$, but not as a - $d a$ - class verb, a fact shown by $(84 b)$, a sentence identical to $(84 a)$, except that $-t a$ - class marker is replaced with the $-d a$ - class.

\footnotetext{
${ }^{38}$ Like all glosses, these are imperfect. The 'remove' gloss is particularly blunt. Better might be something like 'cause to become uprooted/displaced'.
} 
(83a)

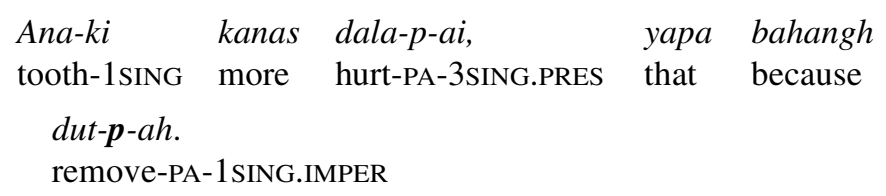

'My tooth is killing me, so pull it out for me'. (dict)

(83b)

$\begin{array}{llll}\text { Pâp- } k i & \text { dut-d-i } & \text { wauh- } d-i d a & y a \\ \text { door-1SING } & \text { remove-DA-ss } & \text { fall-DA-3SING.PAST } & \text { the } \\ \text { pauh-t-uting. } & \end{array}$

'I'm going to nail back on my door which has come off (its hinges)'. (dict)

(84a) Dî muih-ka ya lah-t-ah.

thing flesh-3sing the cook-TA-1SING.IMPER

$\begin{array}{llll}\text { Lah-t-asa } & \text { man } & \text { laih, } & \text { dut-ta-rang. } \\ \text { cook-TA-3SING.NEG } & \text { 2SING } & \text { if } & \text { spoil-TA-3SING.IRR }\end{array}$

'Cook the meat. If you don't cook it, it will spoil/rot'. (notes, 986)

(84b) *Dî muih-ka ya lah-t-ah. Lah-t-asa man laih, dut-da-rang. (notes, 986)

The 'remove' sense is lexically listed as a causative, two-argument, changeof-state sense and, as a consequence, when the root dut- has that denotation, -da- can operate on it to derive an inchoative sense from the lexically listed causative sense, as shown in (83b). By contrast, the 'rot' sense, though a COS sense, is lexically listed as intransitive (being an internally caused change of state sense). Its meaning, then, does not meet the structural description for application of anticausativization and, as such, derivation of a $-d a / w a-$ verb based on a root with this sense is impossible. The situation is illustrated graphically in figure 4. Again, the observation is that a greater number of senses of the root surface in the -ta/pa- classes than in the $-d a / w a-$ classes.

A final example concerns the root sang-, a root more highly polysemous than the previous two. The core meaning of sang-is 'come to be in a state of green or blueness', a sense illustrated in $(85 d)$, where the causative 'cause to become green' sense surfaces in the - $p a$ - class, and in (86), where the inchoative 'become green' sense surfaces as a - $d a$ - class verb. In addition to these core senses, however, there are other intransitive senses that have less to do with the color than they do with something else, and in these cases the 


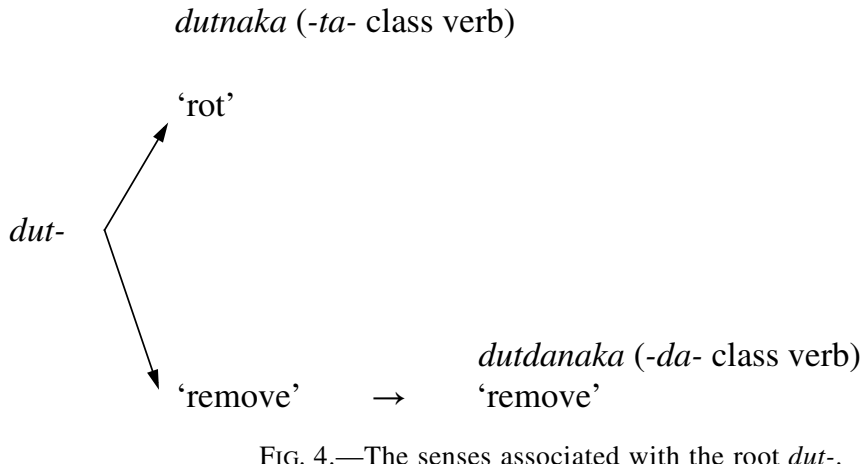

FIG. 4.-The senses associated with the root dut-.

verb is in the -pa-class. In (85a), for example, the verb names an event that has less to do with a change of color than it does with the particular process undergone by cassava when it goes bad. The situation is similar in (85b), where the verb has the sense of 'coming alive', a sense which although it is easy to imagine how it might be related to the core sense of 'become green/blue' is slightly different. Less clearly related to the core sense is the sense illustrated in $(85 c)$, where the verb names the event that is undergone when water becomes clear, e.g., after having been muddy as a result of rain. The crucial point is that all of these extended senses are in -ta/pa- not $-d a / w a-$.

(85a)

$$
\begin{array}{clll}
\text { Joe cassava-1SING let-PA-3SING.DS } & \text { green-PA-3SING.PAST } \\
\text { bakan-t- } i & y a k-t a-s a & d a i & \text { bahangh } \\
\text { sell-TA-SS } & \text { take-out-TA-3SING.NEG } & \text { COP.PAST } & \text { because }
\end{array}
$$

'Joe let my cassava turn green as a result of failing to take it out and sell it'. (notes, 964)

(85b) Mâ daih-ka wat-da

sun hot-ADJ grab-3SING.PAST because die-WA-3SING.PRFCT dai. Katka madi laih buna sang-p-ida COP.PAST but now TOP again green-PA-3SING.PAST

kut $k a$.

lie SENT.KA

'The hot sun got to it, so it died (the grass). But now, it is now in a state of having come back alive'. (notes, 994) 
(85c)

\begin{tabular}{|c|c|c|c|c|}
\hline $\begin{array}{l}\text { Wassik } \\
\text { river }\end{array}$ & $\begin{array}{l}y a \\
\mathrm{DEF}\end{array}$ & $\begin{array}{l}\text { sang-p-ida } \\
\text { green-PA-3SING.PAST }\end{array}$ & $\begin{array}{l}\text { bahangh } \\
\text { because }\end{array}$ & $\begin{array}{l}\text { kut-naka } \\
\text { fish-3sING.INF }\end{array}$ \\
\hline good- & & $\begin{array}{ll}u t & k a . \\
\text { ie } & \text { SENT.KA }\end{array}$ & & \\
\hline
\end{tabular}

'The river cleared up, so it's good to go fishing'. (notes, 988)

(85d) Yang damaska kau wauh-d-uting kal-ki-sungh $\hat{a k a}$ $1 \mathrm{SING}$ grass in fall-DA-1SING.FUT pants-<1SING $\rangle$ these

sang-p-uting.

green-PA-1sING.FUT

'I am going to fall on the grass and make my pants green'. (dict)

$\begin{array}{llll}\text { Muh-ma } & \text { yaka } & \text { sang-d- } i & \text { tung man. } \\ \text { face-2SING } & \text { that } & \text { green-DA-SS } & \text { walk 2SING }\end{array}$

'Your face is turning green'. (notes, 966)

Thus, while the - $p a$ - suffixed root can have a range of metaphorically extended senses on the core sense of the root sang- 'green', as shown in (85), the - $d a$ - suffixed root in (86) has a sense having to do with a change into the color of green. This is consistent with the analysis of -ta/pa- as doing nothing to alter the semantics of the root. The idea is that the root sang-has many senses available to it, all of which can surface when it is suffixed with -pa-, whose sole function is to turn the root into a verbal stem. In contrast, $-d a-$, as an anticausativizer, does alter the sense of the root, and its condition for application is met only by certain kinds of meanings. In its guise as anticausative, $-d a$ - (and -wa-) can operate only on transitive/causative senses of roots, taking a root with transitive/causative meaning and yielding a derived inchoative meaning. For senses that are not transitive/causative, as with many of the senses of the root sang-illustrated in (85), the condition of application of $-d a / w a-$ as anticausativizers is not met, and as such $-d a / w a-$ simply do not surface with those kinds of senses. This state of affairs is shown graphically in figure 5 . The idea illustrated by figure 5 is that roots can have many senses, all of which can surface as -ta/pa- verbs, since all -ta/pa- do is to turn a root into a verbal stem, doing nothing to the lexical semantics of the root. In contrast, $-d a / w a$ - have a lexical semantic function in their use as anticausatives and can only operate on transitive/causative senses, thereby explaining why possible senses of $-d a / w a$ - change-of-state verbs are a subset of the possible senses of $-t a / p a-$ verbs based on the same root.

7. A morphological asymmetry explained by the analysis. There is a certain asymmetry in the morphological behavior of -ta/pa- verbs as compared to $-d a / w a$ - verbs that I believe the proposed analysis sheds light on. 


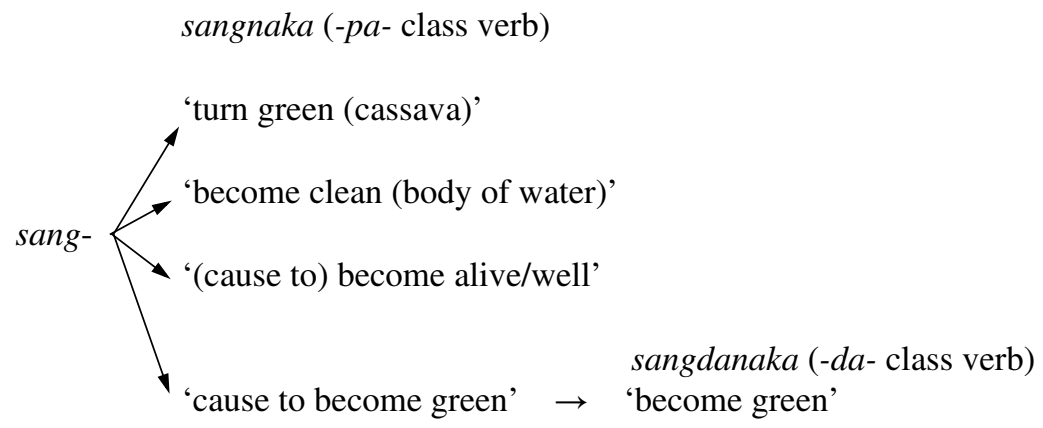

FIG. 5.- The various senses associated with the root sang-.

The issue is that while the $-t a / p a$ - suffixes are absent in the infinitival forms of verbs of those classes ( $87 a$ and $87 b),-d a / w a$ - are present in the infinitival forms of these verbs ( $88 a$ and $88 b)$.

(87a) -pa-themed sangnaka 'to cause to become green'

$\begin{array}{llll}\text { 1SING } & \text { sang-ni-ki } & \text { 1PL.EXCL } & \begin{array}{l}\text { sang-ni-kina } \\ \text { sang-ni-ni }\end{array} \\ & & \text { 1PL.INCL } & \text { sang-na-mana } \\ \text { 2SING } & \text { sang-na-ma } & \text { 2PL } & \text { sang-na-kana }\end{array}$

(87b) -ta-themed sahnaka 'to split'

1SING sah-ni-ki 1PL.EXCL sah-ni-kina

1PL.INCL sah-ni-ni

2SING sah-na-ma 2PL sah-na-mana

3SING sah-na-ka 3PL sah-na-kana

(88a) -da-themed sangdanaka 'to become green'

1 SING sang-da-ni-ki 1PL.EXCL sang-da-ni-kina

1PL.INCL sang-da-ni-ni

2SING sang-da-na-ma 2PL sang-da-na-mana

3SING sang-da-na-ka 3PL sang-da-na-kana

(88b) -wa-themed sahwanaka 'to crack'

\begin{tabular}{|c|c|c|c|}
\hline $1 \mathrm{SING}$ & $s a h-w a-n i-k i$ & $\begin{array}{l}\text { 1PL.EXCL } \\
\text { 1PL.INCL }\end{array}$ & $\begin{array}{l}\text { sah-wa-ni-kina } \\
\text { sah-wa-ni-ni }\end{array}$ \\
\hline & $n a$ & $2 \mathrm{PL}$ & sah-wa-na-mana \\
\hline SIN & $s a h-\boldsymbol{w a}-n a-k a$ & 3PL & sah-wa-na-kana \\
\hline
\end{tabular}


I believe this asymmetry follows rather straightforwardly from the lexical semantic differences between -ta/pa- and - $d a / w a$ - highlighted above. First, the infinitival forms of Ulwa verbs are NOMINAL, as pointed out by Green (1999:chap. 7). The $-n a$ (or - $n i$ under certain phonological conditions) is a noun-deriving suffix, while the $-k i,-m a$, etc. are part of the nominal possessive morphology of the language, as shown in (89).

(89) Nominal possessive paradigm (Green 1999:78)

$\begin{array}{llll}\text { 1SING } & -k i & \text { 1PL.EXCL } & -k i-n a \\ & & \text { 1PL.INCL } & -n i \\ \text { 2SING } & -m a & \text { 2PL } & -m a-n a \\ \text { 3SING } & -k a & 3 \mathrm{PL} & -k a-n a\end{array}$

Since -ta/pa- merely alter the lexical category of a root without effecting changes in its lexical semantics, there is no need for their presence in the infinitival form of verbs, assuming that -na derives a noun directly from the root. In contrast, with the $-d a / w a-$ infinitival forms, the suffixes have to appear, since they effect a change in the lexical semantics. Without these suffixes, the meaning of the root would not be altered and the sense derived via suffixation of $-d a / w a$ - would not be created. Because of this, $-d a / w a-$ have to be present, despite the fact that the derived form is actually not a verb at all. In this way, then, the morphological behavior of the thematic suffixes in the infinitival forms of verbs is not at all mysterious; it follows from their lexical semantics.

This asymmetry in the morphological behavior of $-t a / p a-$ and $-d a / w a-$ class verbs, although it has been previously described by Green (1999), has received no attention in the literature on Ulwa verb classes. Further, previously proposed analyses of Ulwa verb class morphology have no explanation for it. This asymmetry is not, however, unexpected in light of the morphosyntactic and lexical semantic properties of -ta/pa- and - $d a / w a-$ verbs discussed above. In this way, the proposed analysis of Ulwa verb class morphology sheds light on this area of Ulwa morphology, which has previously been a mystery.

8. An outstanding issue: nonalternating $-d a / w a-$ verbs. The analysis of Ulwa verb classes proposed above leaves several issues unresolved, some of which I have noted throughout the paper. Among these are the small number of nonalternating - $d a / w a-$ COS verbs with no -ta/pa- counterpart (see n. 36) and possible transitive uses of -da/wa- verbs discussed in 5 above and n. 37. Another outstanding issue is the analysis of $-d a / w a-$ with non-COS verbs, to which I briefly turn in this section.

In this paper, I have focused largely on the analysis of -ta/pa-verbs, as this is an area where previous analyses of Ulwa verb class morphology 
clearly make empirically incorrect predictions. The facts discussed above lead to an analysis of -ta/pa- as morphemes that do nothing to alter the meaning of the roots they suffix to. As discussed in $\mathbf{5}$ above, this analysis of $-t a / p a$ - has consequences for the analysis of $-d a / w a$ - with COS verbs for which there is a transitive/causative -ta/pa-counterpart. Since -ta/pa- do not alter the meaning of the root, it must be the case that roots from which such verb pairs are derived are lexically causative, with $-d a / w a$ - responsible for deriving an inchoative from a causative. That is, with such roots $-d a / w a-$ must have an anticausative function.

The question remains, however, what the function of $-d a / w a-$ is with roots that form verbs that do not denote COS events and do not participate in the causative/inchoative alternation, i.e., with the roots for which there is only a - $d a / w a$ - and no -ta/pa- verb, as already illustrated for the roots $a i$ - 'cry' and is- 'play', for example, in (8) and (9), repeated in (90) and (91).

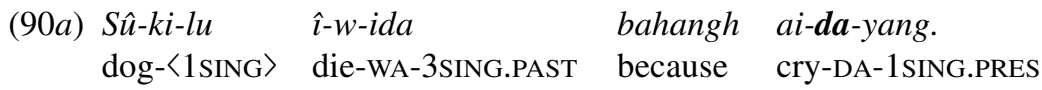

'I am crying because my dog died'. (dict)

(90b) *Baka ya ai-t-ikda.

child the cry-TA-1SING.PAST

‘*I cried the child'. (Hale and Salamanca 2002:48)

(91a) Mining balna yak is-dai.

1PL.INC PL 1PL.INC play-1PL.INC

'We are playing'. (dict)

(91b) *Sumaltingka ya bikiska balna is-ta-i.

teacher DEF child PL play-TA-3SING.PRES

'*The teacher is playing the children'. (Hale and Salamanca 2002:48)

Koontz-Garboden (2007b:chap. 6) outlines preliminary evidence suggesting a unified analysis of $-d a / w a$ - that captures its functions both as anticausative and in its other functions with non-COS verbs, arguing that it marks the MIDDLE VOICE (Klaiman 1991 and Kemmer 1993). Without being specific about exactly what the middle voice is, the observation is simply that $-d a / w a$ - are observed in the same contexts as what have been characterized, particularly by Kemmer (1993), as middle voice morphemes. Principle among such uses is use as anticausative, a function - $d a / w a$ - have already been observed above to have. More important, however, in the context of this section is the fact that the kinds of verbs that $-d a / w a$ - appear on when they are not appearing with alternating change-of-state verbs are verbs that 
in language after language, according to Kemmer, also are marked with the middle voice. These are verbs of speech action, body action, translational motion, cognition, and others (see Koontz-Garboden 1007b:116ff. for details and lists of Ulwa verbs in these classes). Additionally, Koontz-Garboden (2007b) observes that -da/wa- are used in impersonal constructions, another context in which Kemmer and others find the middle voice. Thus, while I have not addressed in this paper the nature of $-d a / w a-$ with nonalternating non-COS verbs, I believe that the analysis I have laid out here is, in fact, consistent with such uses. I hope that future research will demonstrate this more conclusively than is possible in the context of this paper.

9. Concluding remarks. In this paper, I have presented a description and an analysis of Ulwa verb class morphology, based on both older and newly collected data, that challenge the conventional wisdom regarding the functions of this morphology. Previous analyses (Hale and Salamanca 2002 and Hale and Keyser 2002) have treated $-d a / w a$ - as verbalizers of roots that do nothing to their lexical semantics and -ta/pa- as responsible for transitivization. The Ulwa facts, based on this analysis, have been taken as evidence for particular theories of argument structure (Hale and Salamanca 2002, Hale and Keyser 2002, and Juarros 2003). What I have argued is that the Ulwa facts are not best analyzed in this way. Instead, I have shown that treating $-d a / w a-$ as anticausativizers and $-t a / p a-$ as verbalizers of precategorial roots accounts for a range of facts-facts that both contradict and that are unaccounted for by the previous prevailing analysis. Principal among these is the fact that intransitive -ta/pa- verbs are actually widely attested, an observation that casts doubt on Hale and colleagues' treatment of -ta/pa-. Additionally, the lexical semantic and morphological asymmetries discussed above, while they fit well with the analysis proposed here, have not been treated in previous work on the topic. In this way, then, this paper serves both a descriptive and a theoretical function-first, in laying out a number of previously undocumented facts of the language and, second, in showing what the consequences of these facts are for the prevailing analysis which has been cited as evidence for a particular theoretical approach to argument structure. Along the way, I have pointed out several unresolved issues which future research should focus on, and which will no doubt have consequences both for the understanding of Ulwa verbal morphology and semantics and for theories of argument structure more broadly.

\section{REFERENCES}

Alexiadou, Artemis; Elena Anagnostopoulou; And Florian Schäfer. 2006. The properties of anticausatives crosslinguistically. Phases of Interpretation, ed. Mara Frascarelli, pp. 187-211. Berlin: Mouton de Gruyter. 
Belletti, AdRiana, ANd Luigi Rizzi. 1988. Psych-verbs and $\theta$-theory. Natural Language and Linguistic Theory 6:291-352.

Benedicto, Elena. 2005. Alternancias de transitividad en Mayangna (Misumalpa). Handout of talk given at the Universidad de Sonora, Hermosillo, November 10-11, 2005.

Benedicto, Elena, and Ken Hale. 2000. Mayangna, a Sumu language: Its variants and its status within Misumalpan. Indigenous Languages, ed. Elena Benedicto, University of Massachusetts Occasional Papers in Linguistics 20. Amherst: University of Massachusetts.

Charles, Jacinto, and Mateo Torrez. Forthcoming. Morfología y sintagma nominal de los verbos impersonales en la gramática de la lengua sumu-mayangna. B.A. thesis, Universidad de las Regiones Autónomas de la Costa Caribe Nicaragüense (URACCAN).

Chierchia, Gennaro. 2004. A semantics for unaccusatives and its syntactic consequences. The Unaccusativity Puzzle, ed. Artemis Alexiadou, Elena Anagnostopoulou, and Martin Everaert, pp. 22-59. Oxford: Oxford University Press.

Croft, William. 1990. Possible verbs and the structure of events. Meanings and Prototypes, ed. Savas L. Tsohatzidis, pp. 48-73. London: Routledge.

DeLancey, Scott. 1984. Notes on agentivity and causation. Studies in Language 8:181-213.

Doron, Edit. 2003. Agency and voice: The semantics of Semitic templates. Natural Language Semantics 11:1-67.

DowTY, DAVID. 1979. Word Meaning and Montague Grammar. Dordrecht: D. Reidel.

Evans, NichOLas. 2004. Experiencer objects in Iwaidjan languages. Non-Nominative Subjects, ed. Peri Bhaskararao and Karumuri Venkata Subbarao, vol. 2, pp. 77-100. Amsterdam: John Benjamins.

Everett, Daniel L. 2001. Monolingual field research. Linguistic Fieldwork, ed. Paul Newman and Martha Ratliff, pp. 166-88. Cambridge: Cambridge University Press.

Green, Thomas. 1999. A lexicographic study of Ulwa. Ph.D. dissertation, Massachusetts Institute of Technology. 2004. Electronic version of Ulwa dictionary in Green (1999).

Green, Thomas, And Kenneth L. Hale. 1998. Ulwa, the language of Karawala, Eastern Nicaragua: Its position and prospects in modern Nicaragua. International Journal of the Sociology of Language 132:185-201.

Grimshaw, JANe. 1982. On the lexical representation of Romance reflexive clitics. The Mental Representation of Grammatical Relations, ed. Joan Bresnan, pp. 87-148. Cambridge, Mass.: The M.I.T. Press.

Hale, Kenneth L. 1991a. El ulwa, sumu meridional: ¿Un idioma distinto? Wani 11:27-50. . 1991b. Misumalpan verb sequencing constructions. Serial Verbs: Grammatical, Comparative, and Cognitive Approaches, ed. Claire Lefebvre, pp. 1-35. Amsterdam: John Benjamins.

1997. The Misumalpan causative construction. Essays on Language Function and Language Type, ed. Joan Bybee, John Haiman, and Sandra A. Thompson, pp. 199-216. Amsterdam: John Benjamins.

2001. Ulwa (Southern Sumu): The beginnings of a language research project. Linguistic Fieldwork, ed. Paul Newman and Martha Ratliff, pp. 76-101. Cambridge: Cambridge University Press.

Hale, Kenneth L., and Samuel Jay Keyser. 1987. A View from the Middle. Lexicon Project Working Papers 10. Cambridge, Mass.: Center for Cognitive Science, Massachusetts Institute of Technology.

1998. The basic elements of argument structure. Papers from the UPenn/MIT Roundtable on Argument Structure and Aspect, MIT Working Papers in Linguistics 32:73-118. 2002. Prolegomenon to a Theory of Argument Structure. Cambridge, Mass.: The M.I.T. Press. 
Hale, Kenneth L., and Danilo Salamanca. 2002. Theoretical and universal implications of certain verbal entries in dictionaries of the Misumalpan languages. Making Dictionaries, ed. William Frawley et al., pp. 25-59. Berkeley: University of California Press.

$>$ HÄRTL, HoldEN. 2003. Conceptual and grammatical characteristics of argument alternations: The case of decausative verbs. Linguistics 41:883-916.

Haspelmath, Martin. 1993. More on the typology of inchoative/causative verb alternations. Causatives and Transitivity, ed. Bernard Comrie and Maria Polinsky, pp. 87-120. Amsterdam: John Benjamins.

Hopper, Paul, and Sandra A. Thompson. 1980. Transitivity in grammar and discourse. Language 56:251-99.

JACKendoff, Ray. 1990. Semantic Structures. Cambridge, Mass.: The M.I.T. Press.

JuArros, Eva. 2003. Argument structure and the lexicon/syntax interface. Ph.D. dissertation, University of Massachusetts, Amherst.

Kallulli, Dalina. 2006. On unaccusative morphology and argument realization. Ms., University of Vienna.

Kemmer, Susan. 1993. The Middle Voice. Amsterdam: John Benjamins.

Klaiman, M. H. 1991. Grammatical Voice. Cambridge: Cambridge University Press.

Koontz-Garboden, Andrew. 2006a. El estado actual del proyecto de la lengua Ulwa. Ms., Stanford University. $2006 \mathrm{~b}$. The states in changes of state. Proceedings of the Thirty-second Annual Meeting of the Berkeley Linguistics Society (in press). 2007a. Evidentiality and the Ulwa sentential ka. The Ulwa People: Identity and Environment in a Multiethnic Context, ed. Arja Koskinen. Bluefields: URACCAN Press. 2007b. States, changes of state, and the Monotonicity Hypothesis. Ph.D. dissertation, Stanford University. 2009. Anticausativization. Natural Language and Linguistic Theory 27:77-138.

Koontz-Garboden, Andrew, and Itamar Francez. 2009. Possessed propery concepts. Ms., University of Manchester and University of Chicago.

Levin, Beth, and Malka Rappaport Hovav. 1995. Unaccusativity: At the Syntax-Lexical Semantics Interface. Cambridge, Mass.: The M.I.T. Press.

Marcotte, J. P. 2005. Causative alternation errors in child language acquisition. Ph.D. dissertation, Stanford University.

McKoon, Gail, and Talke Macfarland. 2000. Externally and internally caused change of state verbs. Language 76:833-58. 45:1-44

2002. Event templates in the lexical representation of verbs. Cognitive Psychology

Norwood, Susan. 1997. Gramática de la lengua Sumu. Managua: CIDCA.

Parsons, Terence. 1990. Events in the Semantics of English: A Study in Subatomic Semantics. Cambridge, Mass.: The M.I.T. Press.

Piñon, Christopher. 2001. A finer look at the causative-inchoative alternation. Proceedings of Semantics and Linguistic Theory 11. Ithaca, N.Y.: Cornell Linguistics Circle. http://www. phil-fak.uni-duesseldorf.de/ pinon/papers/flcia.html.

Pinker, Steven. 1989. Learnability and Cognition: The Acquisition of Argument Structure. Cambridge, Mass.: The M.I.T. Press.

Rappaport Hovav, Malka, And Beth Levin. 1998. Building verb meanings. The Projection of Arguments: Lexical and Compositional Factors, ed. Miriam Butt and Wilhelm Geuder, pp. 97-134. Stanford, Calif.: CSLI Publications.

Reinhart, TANyA. 2002. The theta system: An overview. Theoretical Linguistics 28:229-90.

Reinhart, TANya, AND TAl Siloni. 2005. The lexicon-syntax parameter: Reflexivization and other arity operations. Linguistic Inquiry 36:389-436. 
Schultze-Berndt, Eva. 2000. Simple and complex verbs in Jaminjung: A study of event categorisation in an Australian language. Ph.D. dissertation, Max Planck Institute for Psycholinguistics.

SMith, CARLOTA. 1970. Jespersen's "move and change" class and causative verbs in English. Linguistic and Literary Studies in Honor of Archibald A. Hill, ed. Mohammad A. Jazayery, Edgar C. Polomé, and Werner Winter, vol. 2, Descriptive Linguistics, pp. 101-9. The Hague: Mouton.

WaLsh, Michael. 1987. The impersonal verb construction in Australian languages. Language Topics: Essays in Honor of Michael Halliday, ed. Ross Steele and Terry Threadgold, pp. 425-38. Amsterdam: John Benjamins.

Wright, SAUNDRA. 2001. Internally caused and externally caused change of state verbs. Ph.D. dissertation, Northwestern University.

Wunderlich, Dieter. 1997. Cause and the structure of verbs. Linguistic Inquiry 28:27-68. 